\title{
Multi-objective optimization of a novel reversible High-Temperature Heat Pump - Organic Rankine Cycle (HTHP-ORC) for industrial low-grade waste heat recovery
}

\author{
Carlos Mateu-Royo*,a, Adrián Mota-Babilonia , Joaquín Navarro-Esbría, Bernardo Peris ${ }^{\mathrm{b}}$, \\ Francisco Molés ${ }^{\mathrm{a}, \mathrm{c}}$, Marta Amat-Albuixech ${ }^{\mathrm{a}}$, \\ ${ }^{a}$ ISTENER Research Group, Department of Mechanical Engineering and Construction, \\ Universitat Jaume I, Campus de Riu Sec s/n, 12071 Castelló de la Plana, Spain \\ ${ }^{\mathrm{b}}$ Grupo de Termotecnia, Escuela Técnica Superior de Ingeniería, Universidad de Sevilla, \\ Camino de los Descubrimientos S/N, 41092 Seville, Spain \\ 'Expander Tech S.L. (Rank) 12600 La Vall d'Uixó, Spain
}

N.B.: This is the PREPRINT (submitted) version of this article. The final, published version of the article can be found at: https://www.sciencedirect.com/science/article/pii/S0196890419308994

\begin{abstract}
Nowadays, a high amount of industrial thermal energy is still lost due to the lack of competitive solutions for energy revalorization. Facing this challenge, this paper presents a novel technology, based on a reversible High-Temperature Heat Pump (HTHP) and Organic Rankine Cycle (ORC). The proposed system recovers low-grade waste heat to generate electricity or useful heat in accordance with consumer demand. Compressor and expander semi-empirical models have been considered for the reversible system computational simulation, being HFC-245fa the working fluid selected. The built-in volume ratio and Internal Heat Exchanger (IHX) effectiveness have been optimized to reach the maximum energy efficiency in each operating condition. Although HFC-245fa exhibits energy performance attributes, its high Global Warming Potential (GWP) is an issue for climate change mitigation. Hence, multi-objective optimisation of the environmentally friendly working fluids Butane, Pentane, HFO-1336mzz(Z), R-514A, HCFO$1233 \mathrm{zd}(\mathrm{E})$ and HCFO-1224yd(Z) has been carried out. The results show that the system proposed, working with HFC-245fa, achieves a Coefficient of Performance (COP) of 2.44 for condensing temperature of $140{ }^{\circ} \mathrm{C}$, operating in HTHP mode, whereas the ORC mode provides a net electrical efficiency of $8.7 \%$ at condensing temperature of $40{ }^{\circ} \mathrm{C}$. Besides, HCFO-1233zd(E) and HCFO$1224 \mathrm{yd}(\mathrm{Z})$ are both appropriate alternatives for the HFC-245fa replacement. These working fluids provide a COP improvement of $9.7 \%$ and $5.8 \%$ and electrical net efficiency improvement of $2.1 \%$ and $0.8 \%$, respectively, compared to HFC-245fa. This paper provides a reference study for further designs and developments of reversible HTHP-ORC systems used for industrial low-grade waste heat recovery.
\end{abstract}

Keywords: High Temperature Heat Pump (HTHP); Organic Rankine Cycle (ORC); energy efficiency; reversible system; decarbonisation

\footnotetext{
* Corresponding author: Carlos Mateu-Royo

Tel: +34964728134

Email: mateuc@uji.es
} 


\section{Nomenclature}

\begin{tabular}{|c|c|}
\hline $\mathrm{AU}$ & heat transfer coefficient $\left(\mathrm{W} \mathrm{K}^{-1}\right)$ \\
\hline C & coefficient \\
\hline $\mathrm{COP}$ & coefficient of performance (-) \\
\hline$h$ & specific enthalpy $\left(\mathrm{kJ} \mathrm{kg}^{-1}\right)$ \\
\hline$m$ & system charge of refrigerant $(\mathrm{kg})$ \\
\hline$\dot{m}$ & refrigerant mass flow rate $\left(\mathrm{kg} \mathrm{s}^{-1}\right)$ \\
\hline$P$ & pressure $(\mathrm{MPa})$ \\
\hline$\dot{Q}$ & thermal power $(\mathrm{kW})$ \\
\hline$r_{v}$ & built-in volume ratio (-) \\
\hline$T$ & temperature $\left({ }^{\circ} \mathrm{C}\right)$ \\
\hline$v$ & specific volume $\left(\mathrm{m}^{3} \mathrm{~kg}^{-1}\right)$ \\
\hline$\dot{V}$ & volumetric flow rate $\left(\mathrm{m}^{3} \mathrm{~s}^{-1}\right)$ \\
\hline$\dot{W}$ & electrical power $(\mathrm{kW})$ \\
\hline VHC & volumetric heating capacity $\left(\mathrm{kJ} \mathrm{m}^{-3}\right)$ \\
\hline \multicolumn{2}{|c|}{ Greek symbols } \\
\hline$\alpha$ & losses coefficient (-) \\
\hline$\varepsilon$ & effectiveness (-) \\
\hline$\eta$ & efficiency (-) \\
\hline$\rho$ & density $\left(\mathrm{kg} \mathrm{m}^{-3}\right)$ \\
\hline \multicolumn{2}{|c|}{ Subscripts } \\
\hline $\mathrm{ad}$ & adapted \\
\hline $\mathrm{amb}$ & ambient \\
\hline $\mathrm{c}$ & energy consumption \\
\hline comp & compressor \\
\hline em & electromechanical \\
\hline ex & machine discharge \\
\hline $\exp$ & expander \\
\hline in & internal \\
\hline is & isentropic \\
\hline $\operatorname{loss} 0$ & constant losses \\
\hline ref & refrigerant or working fluid \\
\hline reg & regenerator \\
\hline $\mathrm{s}$ & installation size \\
\hline su & machine suction \\
\hline vol & volumetric \\
\hline \multicolumn{2}{|c|}{ Abbreviations } \\
\hline GWP & global warming potential \\
\hline $\mathrm{HC}$ & hydrocarbon \\
\hline HCFO & hydrochlorofluoroolefins \\
\hline HFC & hydrofluorocarbon \\
\hline HFO & hydrofluoroolefin \\
\hline HP & heat pump \\
\hline ORC & organic Rankine cycle \\
\hline
\end{tabular}

\section{Introduction}

The Energy Efficiency Directive (EU) 2012/27/EU targeted an energy efficiency increase of 20\% by 2020 using solutions at all the energy chain stages, from production to final consumption, including all energy supplied to industry, transport, households, services and agriculture [1]. The 
challenging Paris Agreement climate goals [2] produced a revision of the Energy Efficiency Directive (EU) 2018/2002 that set an energy efficiency increment of $32.5 \%$ by 2030 [3].

The Fifth Assessment Report (AR5) of the Intergovernmental Panel on Climate Change (IPCC) states that the industrial sector becomes critical for the climate change mitigation since their associated greenhouse gasses (GHG) emissions have been doubled between 1970 and 2010 [4]. Low-grade waste heat, commonly associated with temperatures below $200{ }^{\circ} \mathrm{C}$ [5], represents about one-third of the total waste heat potential estimated in EU, approximately $300 \mathrm{TWh} /$ year [6].

Regarding energy efficiency measures, industrial waste heat recovery demonstrated higher profitability ratios compared to the adoption of renewable energies or the use of technologies for energy consumption reduction [7]. Waste heat can be recovered to be used in close industrial processes with minor heat requirements. On the other hand, a more versatile solution could use the energy available, such as low-temperature power generation or heat pump systems [8]. It has been proven that operating costs and equivalent $\mathrm{CO}_{2}$ emissions could be reduced by $26 \%$, where $18 \%$ of this reduction should be overcome by waste heat recovery technologies [9].

Heat pump and low-temperature power generation systems are technically and economically feasible solutions for heat recovery from low-temperature heat sources. Focusing on the power generation technologies within the low-temperature range, the Organic Rankine Cycle (ORC) is a better alternative than the Kalina cycle, which is more appropriate for waste heat recovery at medium temperatures [10].

While heat pumps can be used to convert waste heat into useful heat, ORC systems can generate clean electricity. Nonetheless, these technologies are not widely used enough in the industry due to different limitations. The ORC is an emerging opportunity that has been successfully installed in industrial applications [11], but heat pump technology requires further development to operate at higher temperatures to produce useful industrial heat. Therefore, waste heat recovery in existing processes represents a technical challenge because additional aspects influence the usability of the available waste heat [12]. The type of process should always be examined to select the appropriate method of waste heat recovery for optimising energy efficiency [10]. The selection of technology mostly depends on the heat sink temperatures [13] and the needs of the specific industrial plant and process [12].

Xia et al. [14] illustrated that combined comparisons of the optimal scenarios and conditions for different waste heat recovery technologies are going to become relevant in the future. Moreover, they highlighted the selection and modification of the working fluid pairs through various technologies. In the medium-scale petroleum refinery study case, the site energy efficiency increased up to $10 \%$ when waste heat recovery technologies were combined to exploit all the available waste heat. The diversity of heat demands can increase site energy efficiency [9]. According to Meyers et al. [15], a higher number of heat pumps operating hours makes it a promising solution for low carbon industrial process heat, and despite the relatively higher energy efficiency of heat pump technology, it is only profitable above $4000 \mathrm{~h}$ per year [16]. However, the maximum yearly operation is limited because these systems only can work if the heat sink is requiring energy. Besides inappropriate temperature levels, between supply and demand by time, location, and quantities can be a discrepancy and diminish the heat pump viability [12].

A more versatile heat pump system could increase the operating hours. Among different options, a reversible system that can operate as a heat pump and organic Rankine cycle can be built sharing most of the components. Using a bypass, a 4-way valve, a modified compressor to allow its operation as an expander, an additional pump, and a series of 3-way valves, the cycle can be reverted [17]. This system has been simulated mainly in buildings with heat storage together in combination with or compared to other technologies. In this way, Dumont [17] has concluded that this technology is profitable in buildings with significant heat demand. Dumont et al. [18] 
provide some insights to design an optimum heat pump-ORC system more competitive than a heat pump combined with photovoltaic solar panels.

On the other hand, Quoilin et al. [19] present the optimisation of some continuous parameters based on favourable performance indicators as well as for practical constraints. Carmo et al. [20] assessed four different control strategies to lessen the adverse effects of cycling in the compressor. The thermal input requirements highly influence the thermal and electrical demand covered by renewable energy, but the control strategies allowed to increase the share of renewable energy used. Schimpf et al. [21] studied this reversible system in three different locations activated by thermal and ground source energy (evacuated tube and flat plate collectors), and they have proven that it is energetically superior compared to a conventional system by the minor additional investment required. Staub et al. [22] suggested that a more promising prospect requires the optimisation of the isentropic efficiencies of the compressor by the application of this idea in larger applications or smaller plant sizes with tailor-made compressor/expander machinery.

As it has been proven, the combination of different waste heat recovery systems in the industry can provide economic and energetic benefits; however, the simulation of innovative heat pumpORC systems has been limited to small domestic applications, in which it is compared with other traditional renewable technologies. However, the integration of these systems into industrial processes could be beneficial. A recent interest appeared in the industrial sector referred to heat pumps that operate at higher temperatures than those of the residential sector. These systems are named as high-temperature heat pumps (HTHPs) due to their capacity to achieve heating temperatures between 100 and $160{ }^{\circ} \mathrm{C}$ [5]. These compression heat pumps provide hightemperature and larger-capacity, becoming one of the practical solutions to meet the requirement of industrial waste heat recovery [23]. Urbanucci et al. [24] conducted an HTHPs integration in trigeneration, showing that this integration provides flexibility to cover variable energy demands along with valuable economic and energy performance improvements. According to Xia et al. [14], recent studies about heat pumps used for low-grade waste heat recovery are developing multiple stages and cascade systems. Moreover, Johnson et al. [25] considered that new working fluids are essential in the development of this emerging technology.

On the other hand, advanced architectures in HTHP are required in order to efficiently cover larger temperature differences between the heat sink and heat source (temperature lift). MateuRoyo et al. [26] proved that with temperature lift above $60 \mathrm{~K}$ two stage configuration with IHX is the one that results in higher performance. Accordingly, Cao et al. [27] considered different two stage configurations than Mateu-Royo et al. [26], and they obtained higher efficiency with two stages using flash tank (with or without intercooler) than the single-stage arrangement. Finally, Mota-Babiloni et al. and Yang et al. $[28,29]$ obtained positive results with HTHP cascades due to the optimisation of the refrigerants for each configuration.

The working fluid used in the HTHP is different from those seen in refrigeration and heat pump applications owing to the unusual higher operating temperatures. HFC-245fa becomes the most common working fluid used in HTHP and ORC, but its high Global Warming Potential (GWP) requires an alternative low-GWP working fluid for sustainable future developments [5]. Natural fluids represent a clean option, but they are highly flammable (in the case of hydrocarbons) or toxic (ammonia) [30]. Alternative options are recently developed through synthetic working fluids as HCFO-1233zd(E), HFO-1336mzz(Z) and HCFO-1224yd(Z), which have been thermodynamic performance analysed in HTHPs by Mateu-Royo et al. [31]. A drop-in or retrofit substitution of HFC-245fa by one of these alternatives can be reduced by approximately $60 \%$ of $\mathrm{CO}_{2}$ equivalent emissions. Frate et al. [32] agreed with Mateu-Royo et al. [31] concluding that HCFO-1233zd(E) provides a good trade-off between energy performance and volumetric heating capacity in comparison with other alternatives. They also concluded that in the final design of the HTHP, several factors influence on the optimal selection of the refrigerant such as the number of compression stages, operating temperatures, and compressor technology, among others. 
Zühlsdorf et al. [33] proved that the zeotropic behaviour of refrigerant mixtures could be used to improve the energy performance of the HTHP.

HTHPs are still in an earlier stage of development, and the first results using different types of prototypes, compressor technologies, working fluids, and configurations are being published. Mateu-Royo et al. [34] have developed an HTHP prototype with scroll compressor that provides a Coefficient of Performance (COP) of 2.23, working with a heat sink and source temperatures of 140 and $80{ }^{\circ} \mathrm{C}$, respectively. Moreover, Bamigbetan et al. [35] present the development of hydrocarbon HTHP with internal heat exchanger and receiver to produce useful heat at $115^{\circ} \mathrm{C}$ using HC-600 as working fluid. The data generated by this prototype was used to calculate the economic and environmental benefits in comparison with boilers in industry, recovering waste heat between 30 and $60{ }^{\circ} \mathrm{C}$ [36]. Chamoun et al. [37] developed an HTHP equipped with a twinscrew compressor that uses water as a working fluid. Two innovations to highlight were the flash tank and a falling film evaporator. Bobelin et al. [38] constructed an HTHP with scroll compressors and included a sub-cooler to deliver heat up to $125{ }^{\circ} \mathrm{C}$ (the composition of the working fluid was not revealed). Finally, Arpagaus et al. [39] developed a prototype using the recently developed synthetic fluid $\mathrm{HCFO}-1233 \mathrm{zd}(\mathrm{E})$. Its high critical temperature allows reaching heating production temperature above $150{ }^{\circ} \mathrm{C}$.

ORC, as the other operational mode of the proposed reversible system for low-grade industrial waste heat recovery, has been more widely investigated than the HTHPs [40]. Similar to HTHPs, the ORC system efficiency is mainly dependent on the heat source temperature, thermophysical working fluid properties, and turbine efficiency. Mahmoudi et al. [41] highlights the critical state, sensible heat and ratio of vaporisation latent heat as the essential refrigerant properties, and includes heat source types, operating conditions and temperature levels to the factors that influence on the final ORC efficiency for waste heat recovery. About the ORC architecture, Braimakis et al. [42] illustrate that ORC recuperative cycles always provide better performance that non-recuperative cycle. Analogous to HTHPs, HFC-245fa is the most popular working fluid [43], and for small scales systems, volumetric machines were the preferred expansion machines, either off-the-shelf, modified compressors or motors because of the lower cost [44]. Then, HCFO$1233 \mathrm{zd}(\mathrm{E})$ is also a promising candidate for ORCs waste heat recovery $[45,46]$. ORCs stage of development is more advanced than HTHPs, and the largest share of publications deals with the application of ORC technology [47], making it already a reliable method to efficiently recover waste heat.

Based on the above-discussed literature review, it can be seen that the combination of HTHP and ORC technologies in a single reversible system is technically viable. Both systems have in common most of the cycle components along with the operating temperatures and working fluids. Hence, the combination of both waste heat recovery technologies will provide higher economic and operating flexibility benefits. Nevertheless, the proposed system has not yet been considered for industrial applications, which becomes a significant waste heat recovery source. Thus, in this paper, we presented a novel reversible HTHP-ORC system for industrial low-grade waste heat recovery. The focus was set on the optimisation analysis and multi-objective low-GWP alternative refrigerant selection to provide guidelines for further design improvement and sustainable development.

The main contributions of the present work are as follows:

- A novel reversible HTHP-ORC system was proposed for low-grade industrial waste heat recovery using HFC-245fa as working fluid, based on semi-empirical compressorexpander validated models.

- A comprehensive energy performance and volumetric machines efficiency evaluation was realised along with an optimisation of the system parameters as a built-in volume ratio and IHX. 
- The semi-empirical performance and efficiencies results from the reversible model using HFC-245fa were used as a reference to realise an alternative low-GWP refrigerants evaluation.

- A multi-objective evaluation for a proper working fluid selection was applied, considering Pentane, Butane, HFO-1336mzz(Z), R-514A, HCFO-1233zd(E) and HCFO$1224 \mathrm{yd}(\mathrm{Z})$ as the alternative low-GWP refrigerants.

To achieve this purpose, the study is structured as follows. Section 2 describes the reversible HTHP-ORC system and the model based on semi-empirical compressor and expander validated models. This section also describes the alternative low-GWP working fluid modelling process. Section 3 introduces the methodology for the built-in volume ration and IHX optimisation processes along with the simulation operating conditions. Section 4 presents the results through detailed performance analysis of the reversible system proposed the optimised performance values and efficiencies. Moreover, this section shows the results of the multi-objective evaluation of alternative low-GWP refrigerants. Finally, the last section contains the relevant conclusions. The results of this study may provide guidelines for the further design and development of reversible HTHP-ORC systems for low-grade waste heat recovery, especially in the industrial sector.

\section{System description and modelling}

In this section, the reversible HTHP-ORC system and its components are described in detail. Moreover, the compressor and expander models are presented and validated. Finally, the thermodynamic properties of selected alternative low-GWP working fluids to HFC-245fa are discussed along with the assumptions considered.

\subsection{Description of the reversible HTHP-ORC system}

The HTHP and ORC systems are mainly composed of the same components, as shown in Fig. 1. Due to this fact, the development of a single system with the capacity of operating either in HTHP or in ORC mode is technically viable, applying some modifications. The development of this system that can operate in both modes represents a challenge, going one step forward in the development of HTHP and ORC technology. The combinations of both technologies maximise the waste heat recovery of the industrial processes and establish the baseline for future analysis and developments of this novel system.

In Fig. 1a, the operation of the reversible system in HTHP mode is shown. This mode is based on the main components of vapour compression cycles with the particularity of including an Internal Heat Exchanger (IHX). The IHX increases the degree of superheating of the refrigerant in the compressor suction line along with the sub-cooling before the expansion process. This improves the system energy efficiency, varying at the same time the rest of the operating parameters, like the heating capacity and discharge temperature, among others [48]. Therefore, an optimisation of the IHX is crucial to reach the maximum energy performance without exceeding the boundaries of the technical limitations.

On the other hand, the basic vapour compression cycle with IHX could be modified to operate in ORC mode and, therefore, allowing a reversible operation in a single system. Fig. 1b shows that evaporator and condenser are standard components of both modes without requiring any modification. Moreover, the heat exchanger used as IHX in HTHP mode can be used as regenerator in ORC mode, resulting as a basic cycle configuration with regeneration in ORC mode. Besides, the scroll compressor used in the HTHP mode requires minor modifications, switching the refrigerant inlet of this component with an additional valve circuit, to operate as an expander in the ORC mode. Finally, the expansion valve is by-passed, and a refrigerant pump is 
added after the condenser. Through these modifications, this novel system can be operated either in HTHP or in ORC mode, by changing the valves position.

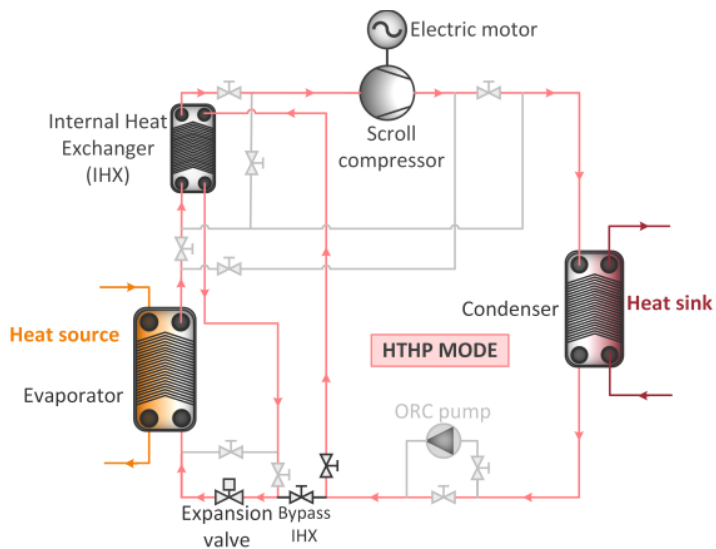

(a)

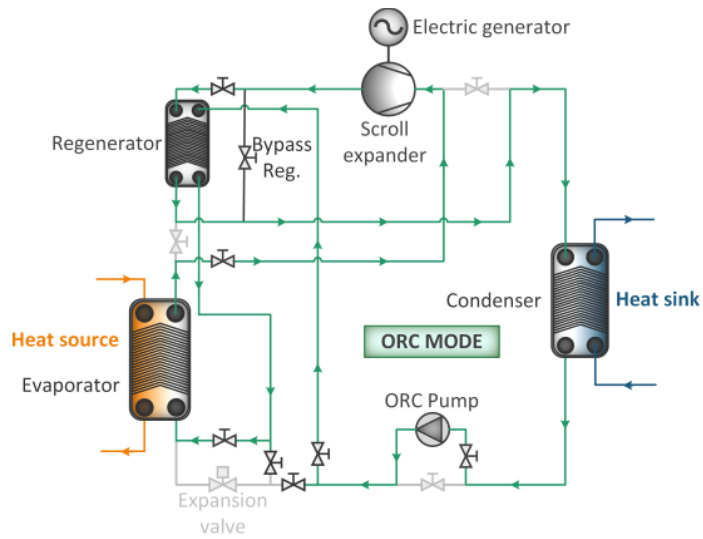

(b)

Fig. 1. Schematic diagram of the reversible HTHP-ORC system, operating in: a) HTHP mode and b) ORC mode.

T-s diagram of the reversible HTHP-ORC system are shown in Fig. 2, with a common evaporating temperature of $90^{\circ} \mathrm{C}$ for both systems and HTHP and ORC condensing temperatures of 140 and $40{ }^{\circ} \mathrm{C}$, respectively. This diagram illustrates the differences between HTHP and ORC thermodynamic cycles along with a graphical description of the concept 'reversible' of the proposed system.

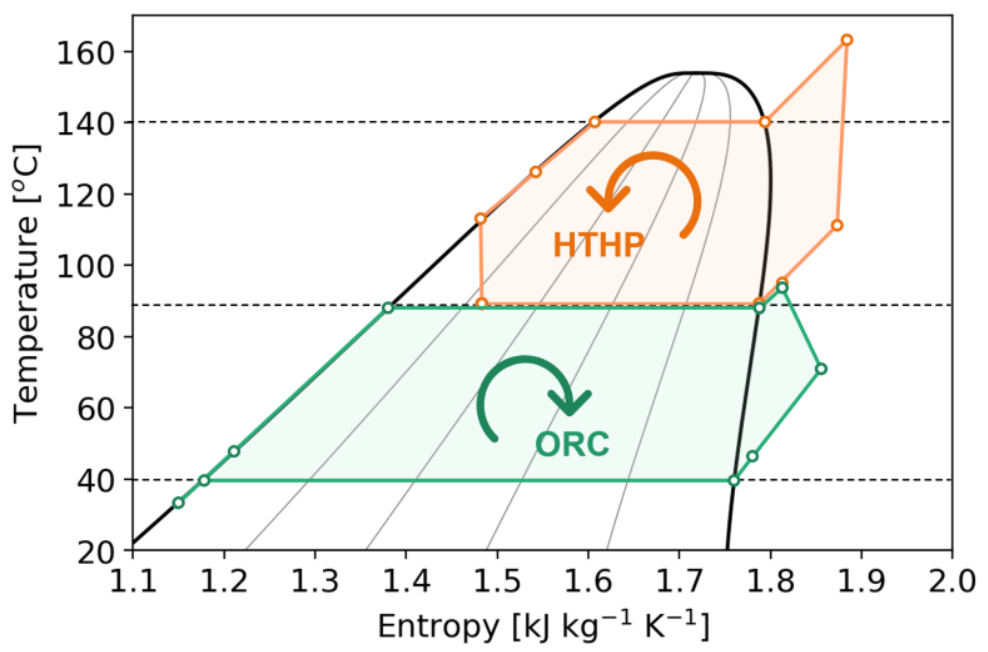

Fig. 2. T-s diagram of the reversible HTHP-ORC system at evaporating temperature of $90{ }^{\circ} \mathrm{C}$ and HTHP and ORC condensing temperatures of 140 and $40{ }^{\circ} \mathrm{C}$, respectively.

\subsection{Compressor-Expander modelling}

The reversible system modelling is built from semi-empirical models of scroll compressor and expander, due to its high efficiency against other technologies $[49,50]$.

The scroll compressor semi-empirical model proposed by Winandy et al. [51,52] could be generalised to scroll compressors using a discharge valve, as Lemort [53] proposed. The motivation is to increase the accurate prediction of the electrical consumption along with the compressor efficiencies. Hence, the modelling of heat pump systems was improved through the modification of compressors that are typically using discharge valves [53]. 
A schematic representation of the proposed compressor model is shown in Fig. 3a, based on the literature reviewed $[50,51,53]$. In this model, the evolution of the refrigerant is decomposed into the following consecutive steps:

- Isobaric supply heating-up ( $s u \rightarrow s u, 1$ )

- Adiabatic mixing with internal leakage $\left(s u,,_{1} \rightarrow s u, 2\right)$

- Adiabatic and reversible compression to the "adapted" pressure imposed by the builtin volume ratio of the machine $(\mathrm{su,2} \rightarrow \mathrm{ad})$

- Adiabatic compression at a constant machine volume $\left(a d \rightarrow e x,,_{2}\right)$

- Adiabatic exhaust pressure drop $\left(e x,,_{2} \rightarrow e x,_{1}\right)$

- Isobaric exhaust cooling-down $\left(e x,,_{1} \rightarrow e x\right)$

The fictitious dissociation of the heat transfer, supply pressure drop, and internal leakage from the actual compression process results in an accurate estimation of the compressor power consumption along with the volumetric and isentropic compressor efficiencies. These parameters are then essentials in the development of the refrigerant comparison model. The complete description of these semi-empirical compressor model, along with the equations used in this paper are described by Lemort [53].

On the other hand, the semi-empirical expander model is adapted from the compressor model proposed by Winandy et al. [51] for hermetic scroll compressors. Similarly to the compressor model, the schematic of the expander model, Fig. 3b, shows consecutive steps of the refrigerant evolution through the expander:

- Adiabatic supply pressure drop $(s u \rightarrow s u, 1)$

- Isobaric supply cooling-down $\left(s u_{1} \rightarrow s u,_{2}\right)$

- Adiabatic and reversible expansion to the "adapted" pressure imposed by the builtin volume ratio of the machine $(s u, 2 \rightarrow a d)$

- Adiabatic expansion at a constant machine volume $(a d \rightarrow e x, 2)$

- Adiabatic mixing between supply and leakage flows $\left(e x,,_{2} \rightarrow e x,_{1}\right)$

- Isobaric exhaust cooling-down or heating-up $\left(e x,,_{1} \rightarrow e x\right)$

Similar to the compressor-expander model, the complete description of these semi-empirical compressor model along with the equations used in this paper are described by Lemort [50] and Lemort et al. [54].

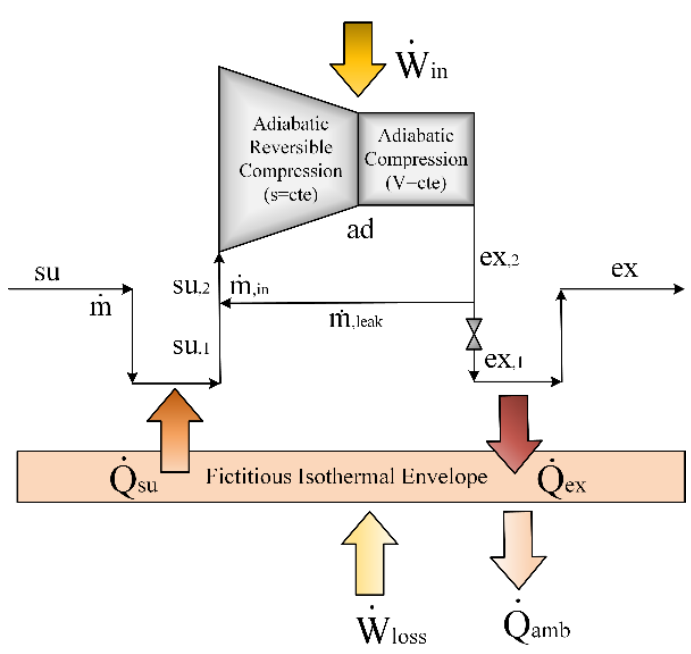

(a)

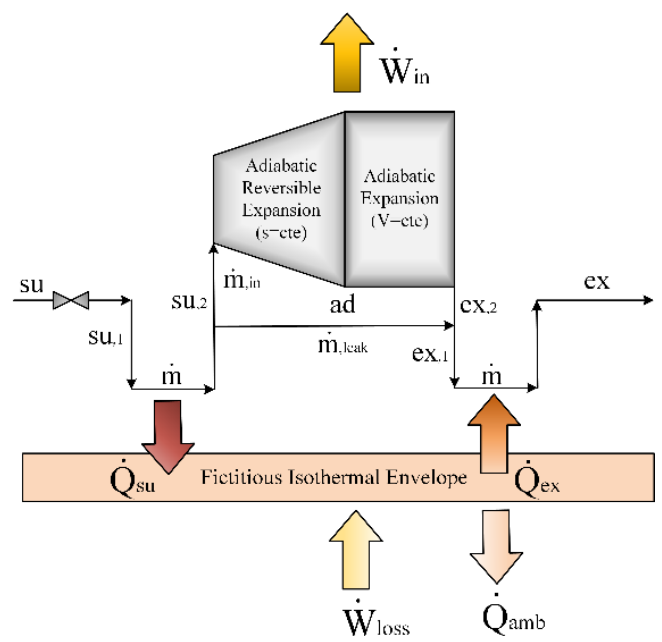

(b) 
Fig. 3. Schematic representation of semi-empirical models: a) Scroll compressor and b) Scroll expander.

\subsection{Reversible HTHP-ORC modelling}

A proper selection and implementation of several geometric constraints make possible the reversible operation between HTHP and ORC cycles. Compressor and expander are volumetric machines that have a fixed geometry. The internal built-in volume ratio $\left(r_{V}\right)$ is dependent on the final and the initial volume in both compressor and expander components. For a given refrigerant at specific conditions, the energy efficiency of the volumetric machine is highly dependent on the built-in volume ratio, which is related to the internal pressure ratio.

Nevertheless, if the system pressure ratio is higher or lower than the internal pressure ratio, overand under-compression/expansion appears. Under this condition, the system operation is considered to be not adapted to the conditions and, therefore, the compressor power consumption is higher, or the expander power generation is lower compared to the optimum values. Hence, a proper design of the internal built-in volume ratio will provide significant energy efficiency for given operating conditions.

The operating pressure ratio in both modes should be similar in order not to penalise energy efficiency. Nevertheless, the optimal built-in volume ratio has different values between compressors and expanders to provide the maximum energy efficiency in both situations [55]. While an expander operates at its maximum energy efficiency, considering lower built-in volume ratio values, a compressor requires higher values of this parameter, as shown in Fig. 4. Henceforth, an optimisation of the built-in volume ratio is required in order to provide a trade-off value between both modes that maximise the overall energy efficiency.

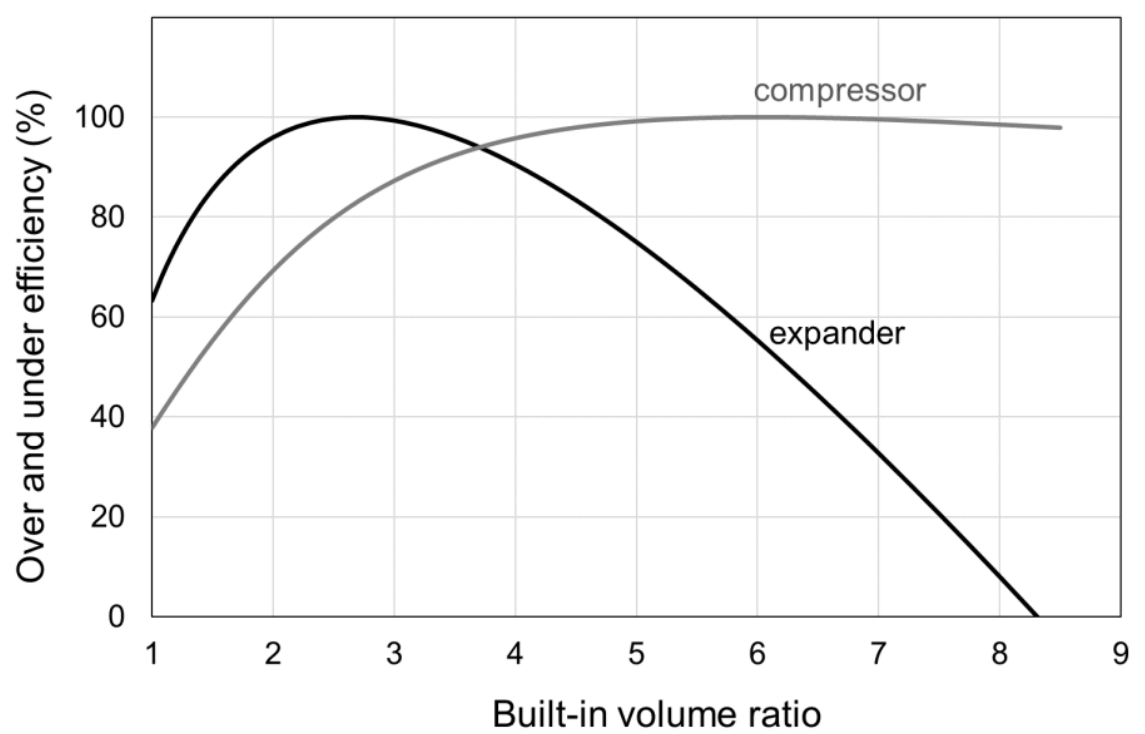

Fig. 4 Over-and under-efficiency at different built-in volume ratio for compressor and expander [55].

On the other hand, the internal heat exchanger in HTHP mode or the regenerator in ORC mode is based on a common component for both configurations. Therefore, the geometry of this component should be the same. While ORC systems present almost no limitations in the regenerator effectiveness value, an HTHP system is highly influenced by the IHX effectiveness value. Higher values of this parameter increase the compressor discharge temperature, and the installation materials along with the lubricant and refrigerant can start to degrade. Due to this fact, the reversible model uses an optimisation IHX effectiveness algorithm that calculates its 
maximum possible value. Then, the regenerator effectiveness is calculated assuming the same AU value for both IHX and regenerator through the NTU method [56], Eq. (1).

$$
\frac{\ln \left(1-\varepsilon_{I H X}\right)}{C_{p, H T H P} \dot{m}_{r e f, H T H P}}=\frac{\ln \left(1-\varepsilon_{R e g}\right)}{C_{p, O R C} \dot{m}_{r e f, O R C}}
$$

\subsection{Validation of the models}

Semi-empirical models of the compressor and expander are developed to obtain several modelling coefficients based on experimental data. Nevertheless, the interest of this paper is the estimation of the performance parameters based on semi-empirical models modification. Hence, implementing the semi-empirical coefficients obtained and validated by Lemort [50] and Lemort et al. [54], it is obtained the performance parameters of the compressor and expander. The experimental coefficients used in compressor and expander semi-empirical models are presented in Table 1.

Table 1. Semi-empirical modelling coefficients for compressor and expander models.

\begin{tabular}{|c|c|c|}
\hline Semi-empirical modelling coefficients & $\begin{array}{c}\text { Compressor } \\
{[50]}\end{array}$ & $\begin{array}{c}\text { Expander } \\
{[54]}\end{array}$ \\
\hline Heat transfer coefficient with the ambient $\left(A U_{a m b}\right)\left[\mathrm{W} \mathrm{K}^{-1}\right]$ & $30\left(\frac{\dot{m}_{r e f}}{0.091}\right)^{0.8}$ & 6.4 \\
\hline Supply heat transfer coefficient $\left(A U_{s u}\right)\left[\mathrm{W} \mathrm{K}^{-1}\right]$ & $20\left(\frac{\dot{m}_{r e f}}{0.091}\right)^{0.8}$ & 21.2 \\
\hline Exhaust heat transfer coefficient $\left(A U_{e x}\right)\left[\mathrm{W} \mathrm{K} \mathrm{K}^{-1}\right]$ & 3 & 34.2 \\
\hline Nominal mass flow rate $\left(\dot{m}_{r e f, n}\right)\left[\mathrm{kg} \mathrm{s}^{-1}\right]$ & 0.091 & 0.12 \\
\hline Leakage area $\left(A_{\text {leak }}\right)\left[\mathrm{mm}^{2}\right]$ & 0.39 & 4.6 \\
\hline Supply port cross-sectional area $\left(A_{s u}\right)\left[\mathrm{mm}^{2}\right]$ & - & 27.43 \\
\hline Mechanical loss torque $\left(T_{l o s s}\right)[\mathrm{N} \mathrm{m}]$ & - & 0.47 \\
\hline Mechanical losses coefficient $(\alpha)[-]$ & 0.23 & - \\
\hline Constant mechanical losses $\left(\dot{W}_{\text {loss }, 0}\right)[\mathrm{W}]$ & 100 & - \\
\hline
\end{tabular}

\subsection{Alternative refrigerants modelling}

The synthetic refrigerant HFC-245fa was used in the semi-empirical models for the identification of the semi-empirical modelling coefficients. Nevertheless, HFC-245fa presents a relatively high Global Warming Potential (GWP) value, which can contribute to aggravating the climate change issue. Hence, other refrigerants with low-GWP may be alternatives to HFC-245fa in this reversible system in order to develop more sustainable technology. The selected low-GWP refrigerants and their main properties are presented in Table 2.

Table 2. Comparative refrigerant properties for HTHP/ORC application. HFC: Hydrofluorocarbons, HFO: Hydrofluoroolefins, HCFO: Hydrochlorofluoroolefins, HC: Hydrocarbons, HFE: Hydrofluorethers. ODP: Ozone Depletion Potential (basis CFC-11=1.0) [57], GWP ${ }_{100}$ : Global Warming Potential for 100-year (basis $\mathrm{CO}_{2}=1.0$ ) [57], Atmospheric lifetime (years) [57], ASHRAE Std. 34 safety class [44].

\begin{tabular}{|c|c|c|c|c|c|c|c|}
\hline Fluids & $\begin{array}{c}\mathbf{T}_{\text {crit }} \\
\left({ }^{\circ} \mathbf{C}\right)\end{array}$ & $\begin{array}{c}\mathbf{P}_{\text {crit }} \\
(\mathrm{MPa})\end{array}$ & $\begin{array}{c}\text { Normal } \\
\text { boiling } \\
\text { point }\end{array}$ & $\begin{array}{c}\text { Suction } \\
\text { density }^{\mathrm{e}} \\
\left(\mathrm{kg} \mathrm{m}^{-3}\right)\end{array}$ & ODP & GWP $_{100}$ & $\begin{array}{c}\text { ASHRAE } \\
\text { Std. 34 } \\
\text { safety class } \\
{[\text { 44] }}\end{array}$ \\
\hline
\end{tabular}




\begin{tabular}{|c|c|c|c|c|c|c|c|}
\hline & & & $\begin{array}{c}(\mathbf{N B P}) \\
\left({ }^{\circ} \mathbf{C}\right)\end{array}$ & & & & \\
\hline HFC-245fa & 153.8 & 3.65 & 15.1 & 40.56 & 0 & 858 & B1 \\
\hline $\begin{array}{c}\text { HC-600 } \\
(\text { Butane) }\end{array}$ & 152.0 & 3.80 & -0.5 & 23.15 & 0 & 4 & A3 \\
\hline $\begin{array}{c}\text { HC-601 } \\
(\text { Pentane) }\end{array}$ & 196.6 & 3.37 & 36.1 & 9.52 & 0 & 5 & A3 \\
\hline $\begin{array}{c}\text { HFO- } \\
1336 m z z(Z))^{\mathrm{a}}\end{array}$ & 171.4 & 2.90 & 33.4 & 25.78 & 0 & 2 & A1 \\
\hline R514A $^{\mathrm{b}}$ & 178.0 & 3.52 & 29.1 & 24.39 & 0 & 2 & B1 \\
\hline $\begin{array}{c}\text { HCFO- } \\
1233 \mathrm{zd}(\mathrm{E})^{\mathrm{c}}\end{array}$ & 166.5 & 3.62 & 18.3 & 32.36 & 0.00034 & 1 & A1 \\
\hline $\begin{array}{c}\text { HCFO- } \\
1224 \mathrm{yd}(\mathrm{Z})^{\mathrm{d}}\end{array}$ & 155.5 & 3.33 & 14.6 & 42.09 & 0.00012 & $<1$ & A1 \\
\hline
\end{tabular}

${ }^{\mathrm{a} O p t e o n}{ }^{\mathrm{TM} M Z}$ from Chemours [58], ${ }^{\mathrm{b}}$ Opteon ${ }^{\mathrm{TM} X P 30}$ (R-514A) from Chemours [59], ${ }^{\mathrm{c}}$ Solstice ${ }^{\circledR} \mathrm{zd}$ from Honeywell [60], ${ }^{\mathrm{d}} \mathrm{AMOLEA}{ }^{\circledR} 1224 \mathrm{yd}$ from AGC Chemicals [61], ${ }^{\mathrm{e}}$ At suction temperature of $95^{\circ} \mathrm{C}$.

In order to simulate the reversible system with alternative low-GWP refrigerants, compressor and expander efficiencies should be corrected according to the thermodynamic properties of the potential candidates. Therefore, isentropic and volumetric efficiencies are adjusted using Eqs. (2) and (3), considering that the refrigerant inside the compressor or expander can be considered as an ideal gas [34].

$$
\begin{gathered}
\eta_{\text {is,low GWP }}=\frac{\left[\left(\frac{P_{2}}{P_{1}}\right)^{\left(\frac{\gamma-1}{\gamma}\right)}\right]_{\text {low GWP }}}{\left[\left(\frac{P_{2}}{P_{1}}\right)^{\left(\frac{\gamma-1}{\gamma}\right)}\right]_{H F C-245 f a}} \cdot \eta_{i s, H F C-245 f a} \\
\eta_{\text {vol,low } G W P}=1-\frac{\left[\left(\frac{P_{2}}{P_{1}}\right)^{\left(\frac{1}{\gamma}\right)}\right]_{l o w G W P}}{\left[\left(\frac{P_{2}}{P_{1}}\right)^{\left(\frac{1}{\gamma}\right)}\right]_{H F C-245 f a}}\left(1-\eta_{v o l, H F C-245 f a}\right)
\end{gathered}
$$

Then, the corrected efficiencies are implemented in a basic compressor-expander model with the same constraints explained in Section 2.2. Moreover, over- and under-expansion/compression effects are implemented in the model, Eqs. (4) and (5), as proposed by Peris et al. [55]. These equations depend on the built-in volume ratio $\left(r_{v}\right)$, which is defined as the geometric volume ratio between the ports of the displacement machine. The optimum value of the $r_{v}$ parameter is affected by several variables, such as the operating conditions or the working fluid used. Therefore, an optimization of the built-in volume ratio has been subsequently included in the model to select a proper suitable working fluid for both operation modes [55].

$$
\eta_{\text {over-under }, \exp }=\frac{\left(h_{s u, 2}-h_{a d}\right)+\frac{P_{a d}-P_{e x, 2}}{\rho v_{a d}}}{h_{a d}-h_{e x, 2, i s}}
$$




$$
\eta_{\text {over-under,comp }}=\frac{h_{a d}-h_{e x, 2, i s}}{\left(h_{a d}-h_{s u, 2}\right)+\frac{P_{e x, 2}-P_{a d}}{\rho v_{a d}}}
$$

Over-under efficiencies for the compressor and expander are included in the equations to calculate the power consumption of the compressor, Eq. (6), and the power generated by the expander, Eq. (7). In addition, the electrical consumption of the ORC pump is presented in Eq. (8).

$$
\begin{gathered}
\dot{W}_{\text {comp }}=\frac{\dot{m}_{\text {ref }, H T H P}\left(h_{\text {comp }, \text { out }, \text { is }}-h_{\text {comp }, \text { in }}\right)}{\eta_{\text {is,comp }} \eta_{\text {em }} \eta_{\text {over-under }, \text { comp }}} \\
\dot{W}_{\text {exp }}=\dot{m}_{\text {ref,ORC }}\left(h_{\text {exp }, \text { in }}-h_{\text {exp }, \text { out }, \text { is }}\right) \eta_{\text {is,exp }} \eta_{\text {em }} \eta_{\text {over-under }, \text { exp }} \\
\dot{W}_{\text {pump }}=\frac{\dot{m}_{\text {ref }, \text { oRC }}\left(h_{\text {pump }, \text { out }, \text { is }}-h_{\text {pump }, \text { in }}\right)}{\eta_{\text {is, pump } p} \eta_{\text {em }}}
\end{gathered}
$$

Finally, the performance of the reversible system can be expressed through two performance parameters: the net electrical efficiency of the ORC $\left(\eta_{n e t}\right)$ by Eq. (9), and the coefficient of performance (COP) of the HTHP by Eq. (10). This analysis assumes normalized values, in which a unit of thermal power input is recovered in both operating modes.

$$
\begin{gathered}
\eta_{\text {net }}=\frac{\dot{W}_{\text {exp }}-\dot{W}_{\text {pump }}}{\dot{Q}_{\text {in }}} \\
\text { COP }=\frac{\dot{Q}_{\text {out }}}{\dot{W}_{\text {comp }}}
\end{gathered}
$$

\section{Methodology}

\subsection{System optimization}

This section describes the optimization process of the built-in volume ratio along with the IHXregenerator. The reversible installation, as a single system, requires sharing the main components of the circuit and therefore, the common circuit components should have the same geometry. Hence, the optimisation of these components is crucial to provide the highest energy efficiency working in both ORC and HTHP modes.

\subsubsection{Built-in volume ratio}

The optimisation of the built-in volume ratio becomes a challenge because the highest energy performance working as compressor or expander demands built-in volume ratio values explained in Section 2.3. Hence, a trade-off between both modes is crucial and therefore, optimisation of this geometrical parameter becomes necessary. The optimisation process is graphically described in Fig. 5. 


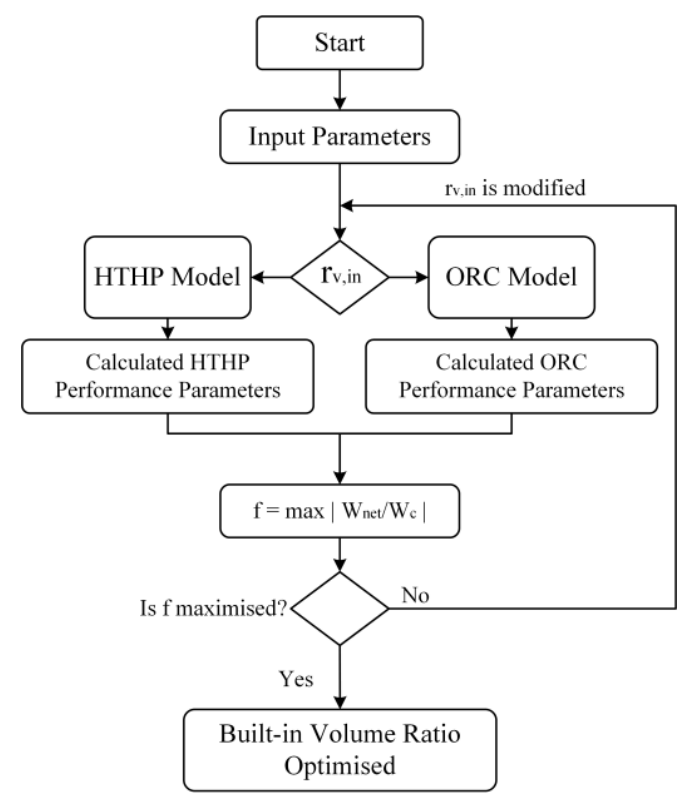

Fig. 5. Built-in volume ratio optimisation process for HTHP-ORC models.

The experimental coefficients for each model described in Section 2.4 are implemented as input parameters in the optimisation model along with the condensation temperatures of both systems and the evaporation temperature, which is related with the industrial waste heat source. These models are developed in the software Engineering Equation Solver (EES) [57], which is linked to the refrigerant thermophysical properties database REFPROP Version 10.0 [58]. Using the Conjugate Directions method implemented in the software EES, the function $f$, shown in Fig. 5, is maximized to find the built-in volume ratio value that provides the highest power production in ORC mode and the lowest power consumption in HTHP mode. Finally, the built-in volume ratio is optimised for one specific condition and therefore, this process is repeated for each simulation condition included in this study.

\subsubsection{Internal heat exchanger (IHX)}

After optimising the built-in volume ratio, the IHX should be optimised in order to maximise the energy efficiency of the whole system. Higher IHX effectiveness increases the degree of sub cooling and superheating degree in the system and therefore, the energy efficiency in both systems increase. Nevertheless, it also results in higher compressor discharge temperature [31], which should be limited due to the installations materials, refrigerants and lubricants thermal limitations. Hence, the built-in volume ratio algorithm, described in the previous section, is followed by the IHX effectiveness optimisation algorithm, presented in Fig. 6. 


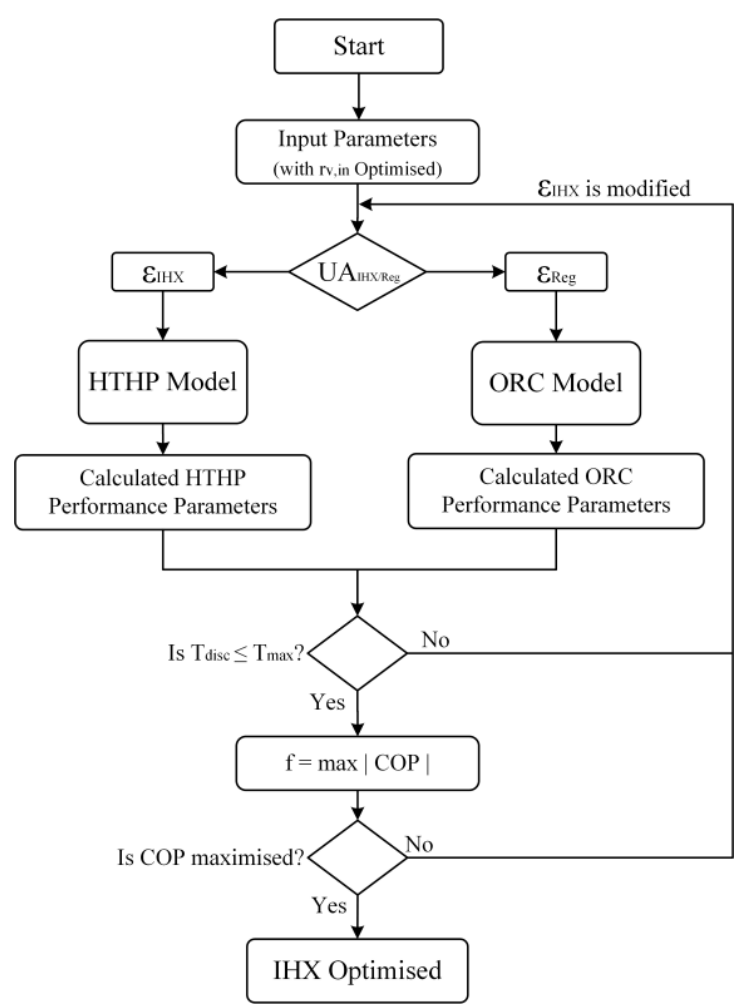

Fig. 6. Internal Heat Exchanger (IHX) optimisation process for HTHP-ORC models.

The IHX optimisation algorithm receives the optimised results of the built-in volume ratio algorithm as input parameters. The compressor discharge temperature is limited to $175^{\circ} \mathrm{C}$ in order to ensure the material resistance as well as to prevent the refrigerant and lubricant tested degradation [31]. Following the previous optimisation methodology, the Conjugate Directions method implemented in EES is used to maximise the COP without exceeding the maximum compressor discharge temperature. Finally, the regenerator effectiveness of ORC system is calculated using the NTU method with the optimised IHX effectiveness and assuming equal UA in the IHX-Reg., for both ORC and HTHP modes. This assumption is reasonable because each mode works with the same refrigerant, and the heat exchanger has a single geometry for both modes.

Finally, the optimisation process provide the optimum the built-in volume ratio and IHX-Reg effectiveness, which provides the maximum performance efficiency with a compromise between HTHP and ORC modes. Depending on the application or requirements, both algorithms can be adapted to find the optimised parameters that prioritize HTHP or ORC mode. Nevertheless, the algorithms in this study are developed to find the equilibrium between both operating modes.

\subsection{Simulation of the operating conditions}

This section describes the operating conditions proposed for the reversible system modelling. The heat absorbed by the evaporator $\left(\dot{Q}_{o}\right)$, the input parameter of the model, is considered constant for all the operating conditions to end with a comparative analysis. Finally, Table 3 presents the operating conditions of both cycles.

Table 3. Operating parameters of the reversible system modelling.

\begin{tabular}{|c|c|}
\hline Parameters & Numeric values \\
\hline Evaporating temperature $\left({ }^{\circ} \mathrm{C}\right)$ & $70-100$ \\
\hline HTHP condensing temperature $\left({ }^{\circ} \mathrm{C}\right)$ & 145 \\
\hline ORC condensing temperature $\left({ }^{\circ} \mathrm{C}\right)$ & 40 \\
\hline
\end{tabular}




\begin{tabular}{|c|c|}
\hline Superheat degree $(\mathrm{K})$ & 15 \\
\hline Sub-cooling degree $(\mathrm{K})$ & 5 \\
\hline Electromechanical efficiency $\left(\eta_{\text {em }}\right)$ & 0.75 \\
\hline ORC pump efficiency $\left(\eta_{\text {pump }}\right)$ & 0.9 \\
\hline
\end{tabular}

\section{Results and discussions}

\subsection{Reversible HTHP-ORC}

This section presents the results obtained by the semi-empirical reversible model working with HFC-245fa as working fluid. Firstly, the system optimisation results are exposed, comparing the maximum efficiency in both modes, which depends on the built-in volume ratio along with the maximum point optimised. Then, an analysis of different condensing temperatures in both systems with a fixed evaporating temperature is realised in order to provide a complete view of the system behaviour. Finally, the energy performance of both modes is presented along with the compressor and expander efficiencies.

\subsubsection{System optimisation}

The optimisation of the built-in volume ratio is crucial in volumetric machines and especially, for the reversible system proposed in this paper. Considering that the same component is operating as compressor and expander, the same geometry is required for both HTHP and ORC modes. Nevertheless, the maximum efficiency points in HTHP and ORC modes are different as the evaporating temperature varies. For lower evaporating temperatures, HTHP mode requires higher built-in volume ratio than working in ORC mode, as shown in Fig. 7. However, this situation changes when the system operates at higher evaporating temperatures. In these conditions, the ORC mode requires higher built-in volume ratio values than HTHP mode. Therefore, higher evaporating temperatures decrease the built-in volume ratio requirements in HTHP modes, whereas this requirement increase working as ORC mode. These built-in volume ratio requirements differences in both modes represents a challenge to find the optimum value. Hence, using the optimization algorithm presented in Section 3.1.1, the optimum built-in volume ratio for the reversible system working in both modes is presented in Fig. 7.

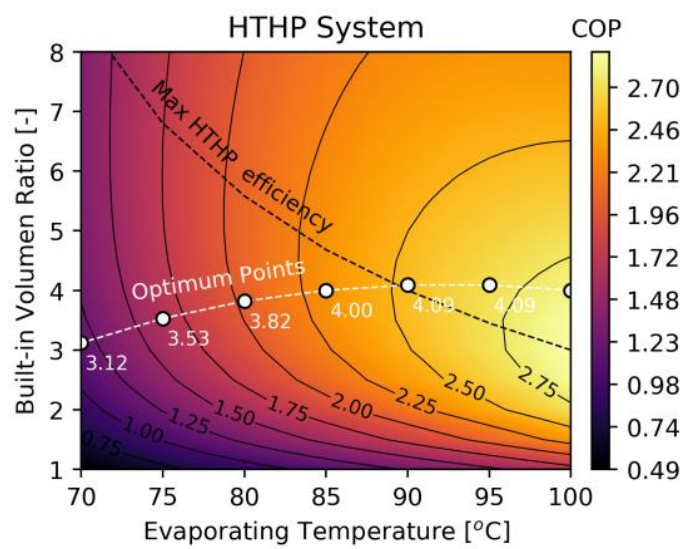

(a)

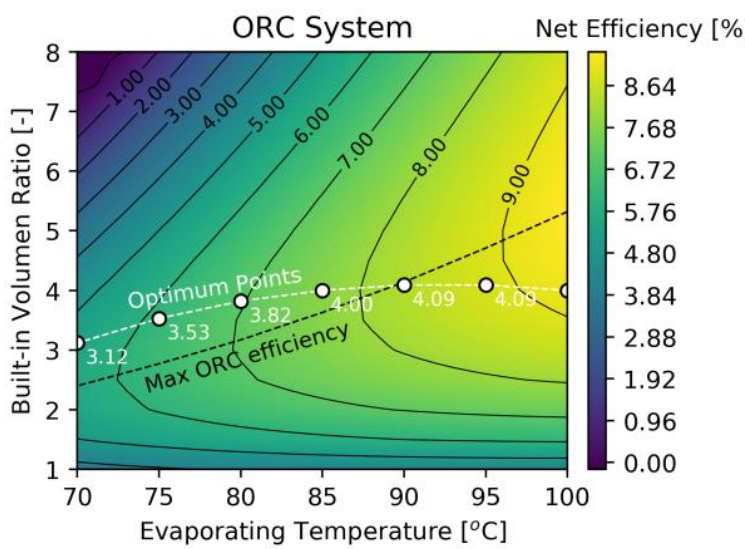

(b)

Fig. 7. Optimised values of built-in volume ratio for reversible system working in: a) HTHP mode and b) ORC mode.

In order to provide a complete view of the proper built-in volume ratio, this parameter has been optimised for different condensing temperatures in HTHP and ORC modes, fixing the evaporating temperature at $85^{\circ} \mathrm{C}$, as shown in Fig. 8. As the HTHP condensing temperature increases, the reversible system requires higher built-in volume ratio in order to provide the maximum energy 
efficiency. Nevertheless, an ORC condensing temperature increment produces the contrary reaction, decreasing the requirements system in built-in volume ratio. Similar to the Fig. 8, there is difference about the built-in volume ratio requirements for both modes. Therefore, depending on the operating temperatures and the applications, the reversible system will required a specific optimisation of this parameter to provide the highest energy performance.

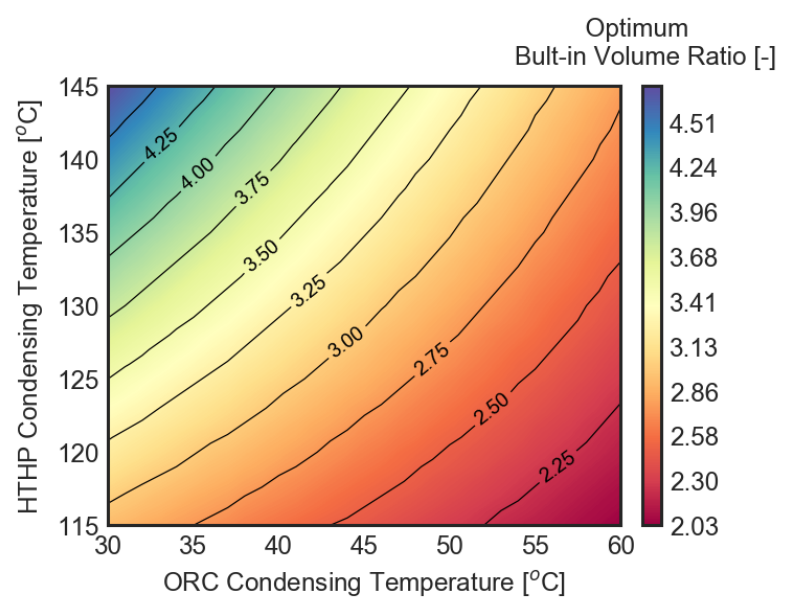

Fig. 8. Optimum built-in volume ratio for different HTHP-ORC condensing temperatures with a fixed evaporating temperature of $85^{\circ} \mathrm{C}$.

\subsubsection{Performance evaluation}

In Fig. 9, the COP and net efficiency of HTHP and ORC modes are presented, respectively. As the evaporating temperature rises, both the energy parameter increases. These are expected results because as the evaporating temperature increases, the distance between the heat source and heat sink for HTHP is reduced and therefore, the compressor requires lower power consumption, providing higher COP. On the contrary, as the evaporating temperature increases, the heat source and sink in ORC mode is increasing. Nevertheless, this increase provides an advantage for ORC mode because the pressure ratio between the expander inlet and outlet increases and therefore, higher power can be generated.

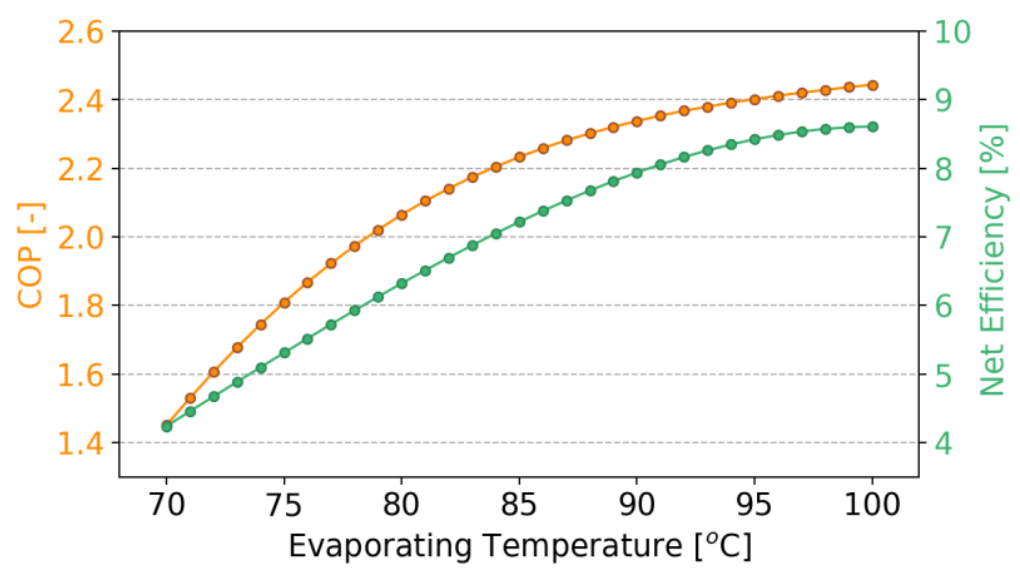

Fig. 9. COP and net efficiency results of the semi-empirical reversible system modelling.

Finally, semi-empirical modelling provides the compressor-expander isentropic efficiencies. These values have notable importance because establishing the baseline for the low-GWP alternative refrigerant analysis explained in Section 2.5. Fig. 10 shows the main compressor and expander isentropic and volumetric efficiency results at different evaporating temperatures. This semi-empirical efficiency results will be corrected for each alternative low-GWP refrigerant in 
order to estimate the compressor and expander efficiencies and therefore, realise the multiobjective comparison.

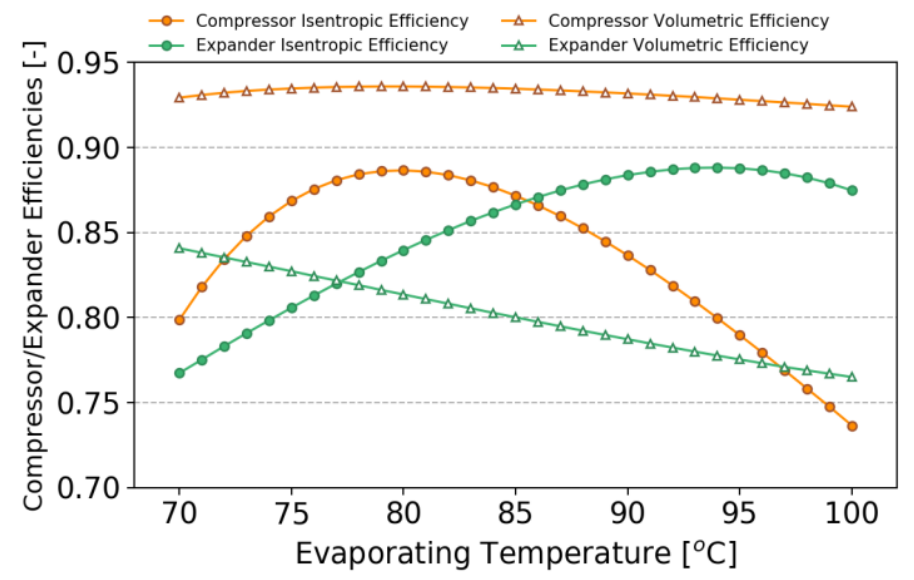

Fig. 10. Compressor-expander isentropic and volumetric efficiencies from semi-empirical reversible modelling.

\subsection{Alternative Low-GWP refrigerants}

This section presents the results of the alternative low-GWP refrigerants for HFC-245fa in the reversible system proposed. These results are based on the semi-empirical models and the corrected efficiencies, depending on the thermophysical properties of each refrigerant. The results of this section will illustrate the benefits of different refrigerants from energy and installation size points of view.

\subsubsection{Corrected isentropic and volumetric efficiencies}

Isentropic and volumetric efficiencies are highly related to the thermophysical properties of the refrigerant uses in the system. Therefore, the efficiencies estimated with semi-empirical models using HFC-245fa as refrigerant can be used as a baseline in order to calculate the alternative lowGWP refrigerants efficiencies through the Eqs. (3) and (4).

Fig. 11a shows the results of the corrected isentropic efficiencies for compressor and expander. On the one hand, HCFOs and Butane present higher compressor isentropic efficiency than HFC245fa, while R-514A shows comparable values to the traditional HFC-245fa. On the other hand, Pentane and HFO-1336mzz(Z) have considerably lower isentropic compressor values due to their different thermophysical properties to HFC-245fa. In contrast, the isentropic efficiencies in the expander show completely different behaviour than working as a compressor, as shown in Fig. 11b. In this case, Pentane and HFO-1336mzz(Z) present the highest isentropic efficiency working as expander followed by R-514A. Finally, although HFOs and Butane show the lowest expander isentropic efficiencies, their values are still higher than HFC-245fa. 


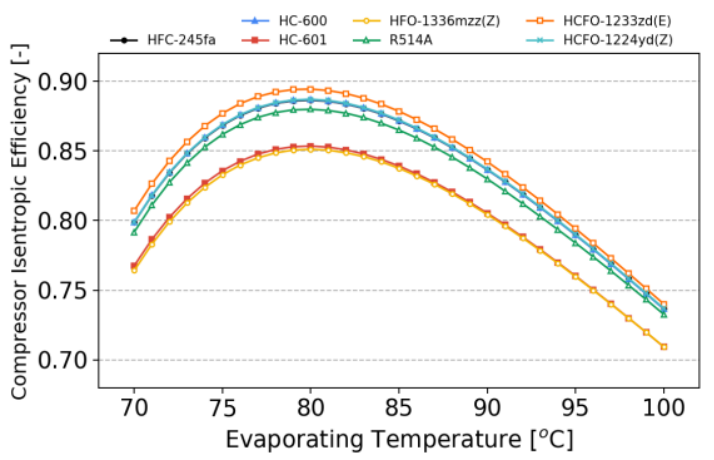

(a)

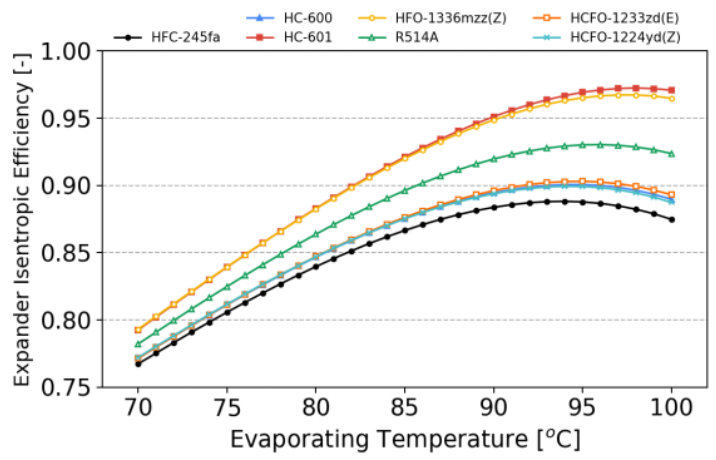

(b)

Fig. 11. Corrected isentropic efficiencies at different evaporating temperatures working as: a) Compressor and b) expander.

The volumetric efficiencies of the compressor and expander are presented in Fig. 12. In this case, HFO-1336mzz(Z) shows the highest volumetric efficiency working as compressor, followed by Pentane and R-514A, as shown in Fig. 12a. While these three refrigerants present higher compressor volumetric efficiency than HFC-245fa, the other refrigerants show lower values of this parameter, being Butane the refrigerant with the lowest volumetric compressor efficiency. As expander, the refrigerants show again a significantly different behaviour, as shown in Fig. 12b. In this case, Butane and HCFOs have higher volumetric efficiencies than HFC-245fa, being Butane the refrigerant with the highest volumetric efficiency. Nevertheless, HFO-1336mzz(Z), R-514A and Pentane have lower expander volumetric efficiencies, showing the HFO the lowest value.

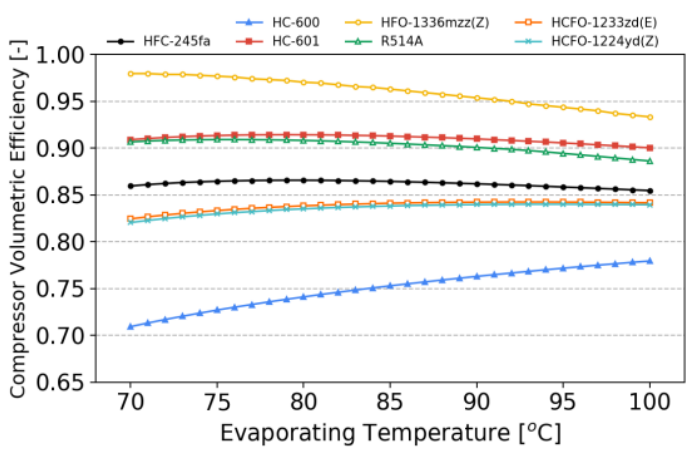

(a)

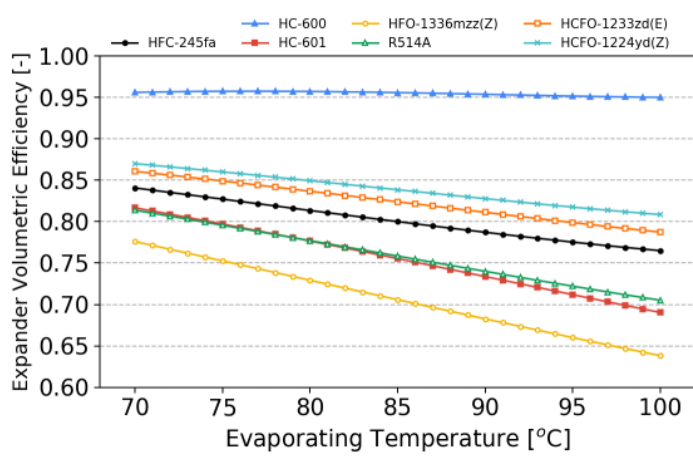

(b)

Fig. 12. Corrected volumetric efficiencies at different evaporating temperatures working as:

a) Compressor and b) expander.

\subsubsection{Optimized evaluation}

This section presents the results of the optimised built-in volume ratio for the reversible system proposed along with the IHX-Reg. effectiveness optimisation. Before the optimisation processes mentioned in Section 3.1, the optimised results will illustrate the main difference of each refrigerant in the system.

Fig. 13 shows the results of the optimised built-in volume ratio for each refrigerant at different evaporating temperatures. As the evaporating temperature increases, the optimum built-in volume ratio increases for each refrigerant until an evaporating temperature of $90^{\circ} \mathrm{C}$, where this parameter shows a slight decrement. This behaviour is caused due to the maximum efficiencies trend of both HTHP and ORC systems presented in Fig. 7. At the evaporating temperature of $90{ }^{\circ} \mathrm{C}$, the maximum efficiency lines of HTHP and ORC system cross among each other, resulting in the optimum built-in volume ratio decrease showed in Fig. 13. 
HFO-1336mzz(Z) presents the highest optimised built-in volume ratio value, whereas Butane shows the lowest value of this parameter. All the refrigerants, apart from HFO-1336mzz(Z) present a lower optimum built-in volume ratio for operating in both HTHP and ORC mode. Moreover, most of the refrigerants simulate have close values to HFC-245fa, and therefore, the reversible systems design for HFC-245fa can operate with other refrigerant with a slight difference from built-in volume ratio point of view.

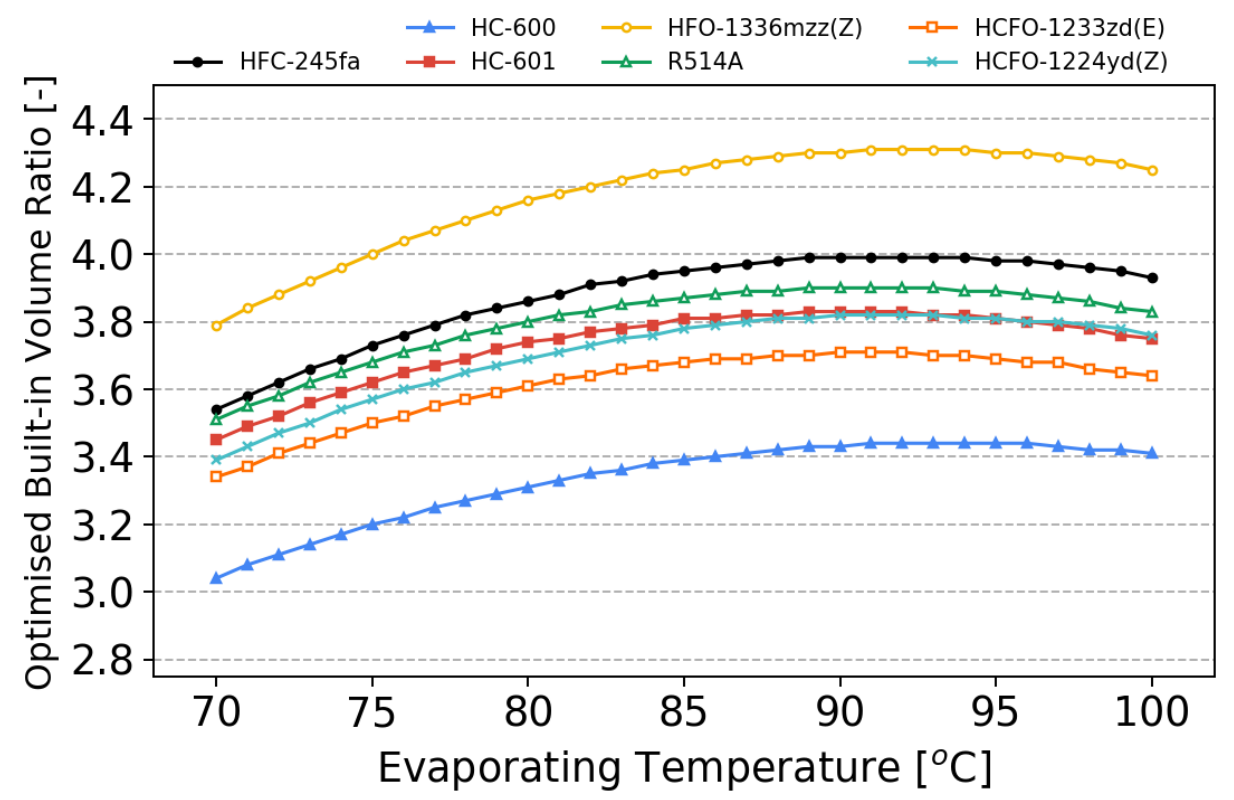

Fig. 13. Optimised built-in volume ratio for each alternative low-GWP refrigerant at different evaporating temperatures.

Fig. 14 shows the effectiveness of the IHX-Regenerator working as a compressor or expander. Both parameters are proportional because is the same heat exchanger for both modes and therefore, similar behaviour in both HTHP and ORC mode is expected. As the evaporating temperature increases, the IHX-Reg value decreases due to the maximum compressor discharge temperature allowed. HFO-1336mzz(Z) and Butane are the refrigerants that can operate with the highest IHX effectiveness values without exceeding the maximum compressor discharge temperature. Contrary, HCFO-1233zd(E) and R-514A have the lowest values of effectiveness, and therefore, the performance improvement caused by the IHX is expected to be lower.

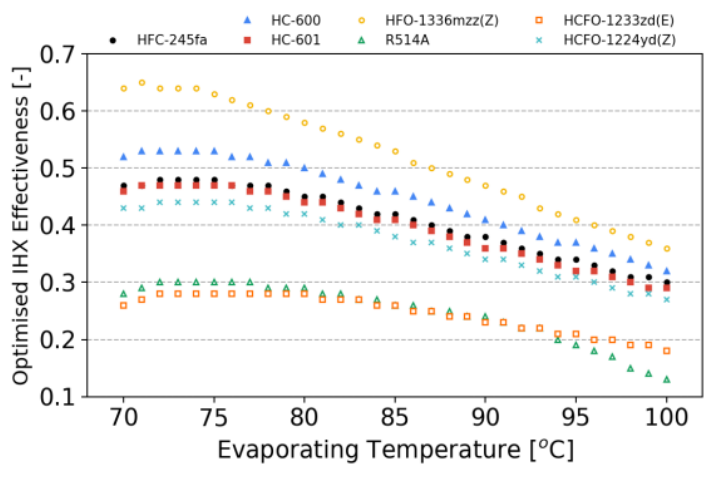

(a)

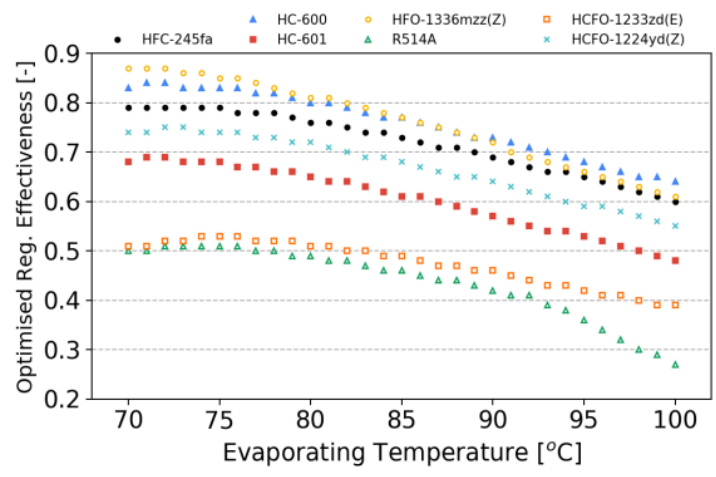

(b)

Fig. 14. Optimised effectiveness at different evaporating temperatures: a) IHX and b) Regenerator

\subsubsection{Performance comparison}


This section presents the performance results for the alternative low-GWP refrigerants along with the reference fluid HFC-245fa. Moreover, an analysis of the compressor power consumption and expander power generation is realised in order to provide a complete view of the reversible system.

Working as HTHP, the performance energy efficiency for each refrigerant is estimated with the COP, as shown in Fig. 15. While Butane shows lower COP than the traditional working fluid HFC-245fa, the other candidates present higher energy performance values. Pentane, HFO$1336 \mathrm{mzz}(\mathrm{Z})$ and R-514A, which is a blend of HFO-1336mzz(Z), have the highest values of COP followed by the HCFOs (HCFO-1233zd(E) and HCFO-1224yd(Z)).

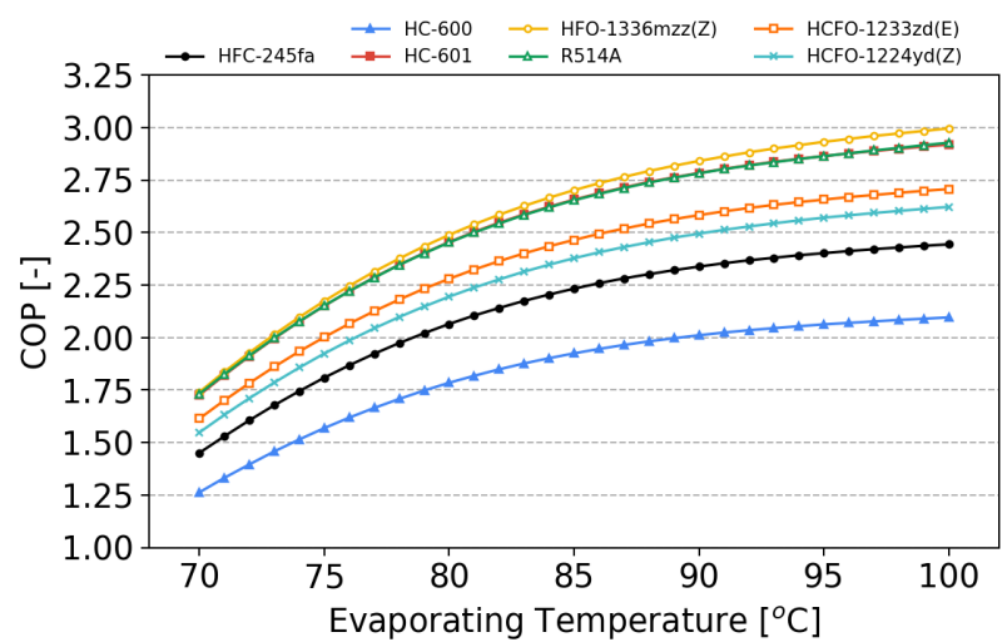

Fig. 15. COP results for the alternative low-GWP refrigerants and HFC-245fa at different evaporating temperatures.

Similar to HTHP mode, the highest net efficiency values working as ORC are shown in Pentane and HFO-1336mzz(Z), followed by its blend, R-514A. In this case, HCFOs are close to HFC245fa behaviour, and Butane shows slightly higher net efficiency values, as shown in Fig. 16.

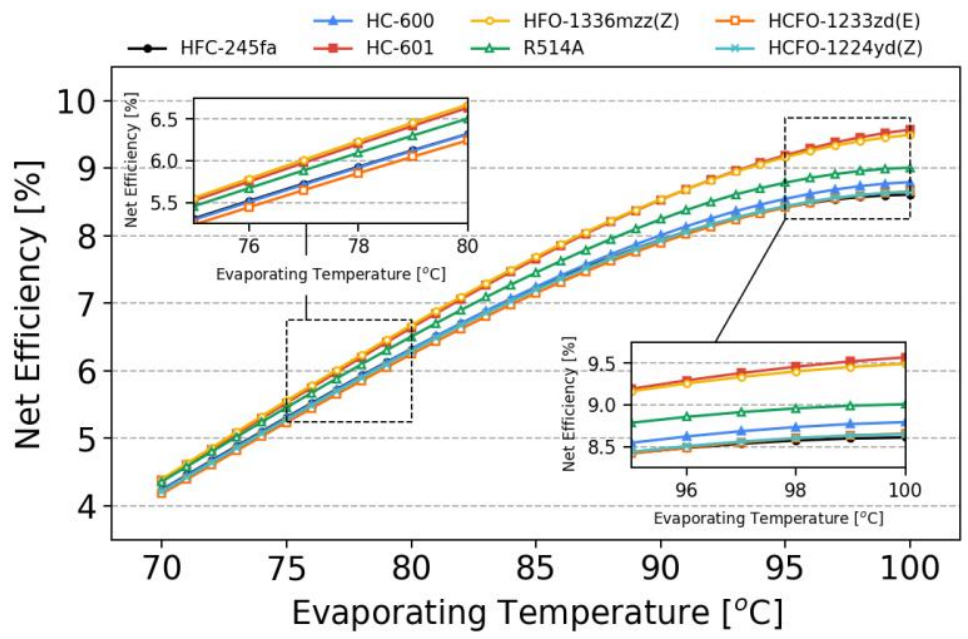

Fig. 16. Net efficiency results for the alternative low-GWP refrigerants and HFC-245fa at different evaporating temperatures.

Finally, the compressor power consumption is compared with the expander power generation in order to illustrate the possibility to use the same component working as motor and generator, as shown in Fig. 17. At lower evaporating temperatures, the electric motor working as a compressor 
should have 25 times the capacity of the generator. Nevertheless, this difference is reduced as the evaporating temperature increases. At higher evaporating temperatures, the power capacity between the motor (compressor) and expander (generator) is reduced, obtaining values between 5-8 times. Although the power capacity difference is relatively small, all the refrigerants analysed will require different power capacities for the electric motor and generator. Hence, a single component can be used as a compressor or expander, but electric motor and generator should be different. One possible solution is connecting the compressor/expander in a single shaft along with an electric motor and generator with different capacities that transmit or receive the power.

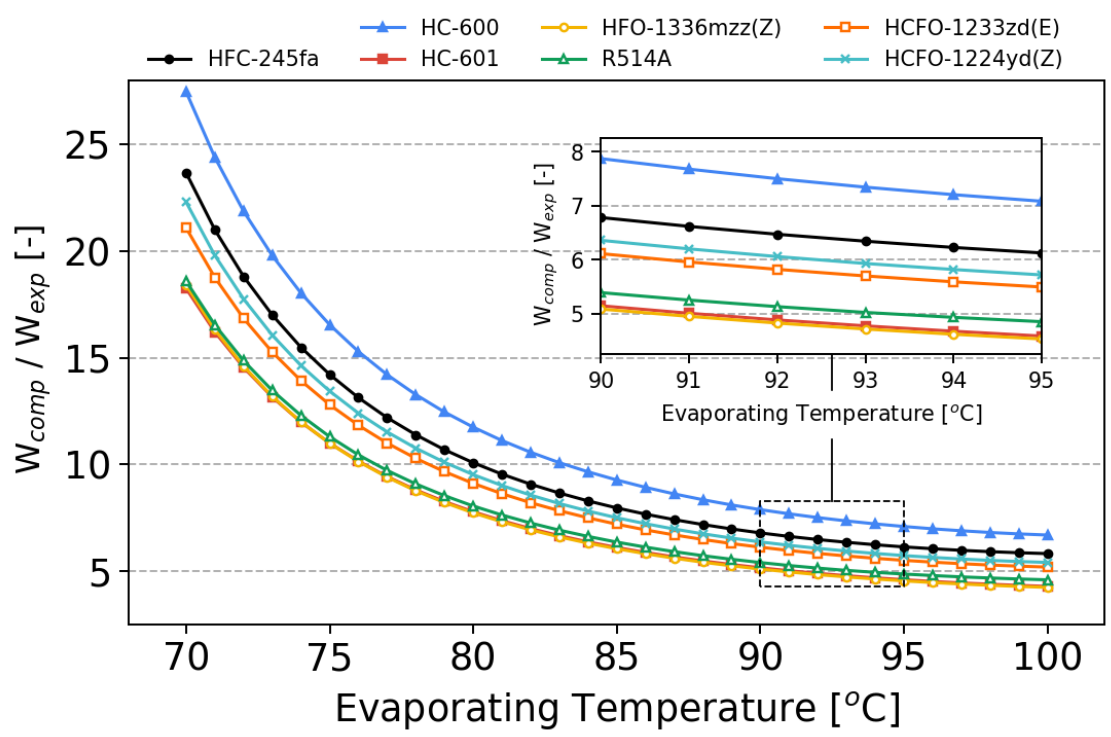

Fig. 17. Electric power differences between the motor and generator capacities.

\subsubsection{Multi-objective evaluation}

The evaluation between different alternative low-GWP refrigerants requires more than one parameter to realise the optimum selection and most cases, different scenarios provide a variety of optimal solutions. In vapour compression systems, the proper refrigerant selection depends on the application, energy efficiency and the installation size. Nevertheless, for a singular application, the refrigerant that provides the highest energy efficiency often requires larger installation size and vice versa. Due to this fact, a multi-objective evaluation is proposed in this paper, in order to compare the refrigerant behaviour working as HTHP, ORC or as a reversible system in different scenarios. Five different scenarios are proposed in this analysis comparing the energy efficiency of each refrigerant and the installation size.

In order to realise this multi-objective evaluation, two different coefficients are prosed that will weigh the relevance of the energy efficiency and installation size, depending on the scenario. Hence, the scenario 1 has the consumption coefficient $\left(C_{c}\right)$ in the maximum value whereas the installation size coefficient $\left(C_{S}\right)$ has the lowest possible value. The consumption and size coefficients weight are gradually varying in the different scenarios until scenario 5, which is the opposite case of scenario 1 . The compressor and ORC pump power consumption corresponds to the energy efficiency evaluation and the compressor and expander volumetric flow rate illustrate the installation size evaluation. These parameters are presented in the multi-objective analysis as the relative difference between the alternative low-GWP refrigerants and HFC-245fa, multiplying by consumption coefficient $\left(C_{c}\right)$ and installation size coefficient $\left(C_{S}\right)$ in each scenario.

Fig. 18 shows the multi-objective evaluation considering that the reversible system will be operating only as HTHP or ORC, without being reversible. As HTHP, Pentane, HFO-1336mzz(Z) 
and R-514A are the potential candidates to HFC-245fa in scenario 1 where the energy efficiency has the whole weight, as shown in Fig. 18a. Nevertheless, other refrigerants as Butane and HCFOs be positioned as potential candidates as the installation size increase the weight in the evaluation. Therefore, Pentane, HFO-1336mzz(Z) and R-514A have lower energy consumption and require larger installation size, whereas the other refrigerants have higher power consumption but require smaller installation size. Similar to HTHP mode, Pentane, HFO-1336mzz(Z) and R-514A are the proper candidates from an energy efficiency point of view (scenario 1), as shown Fig. 18b. Nevertheless, Butane becomes a potential candidate taking into account only the installation size (scenario 5). Finally, the most equilibrated candidates between the energy performance and the installation size are HCFO-1233zd(E) and HCFO-1224yd(Z).

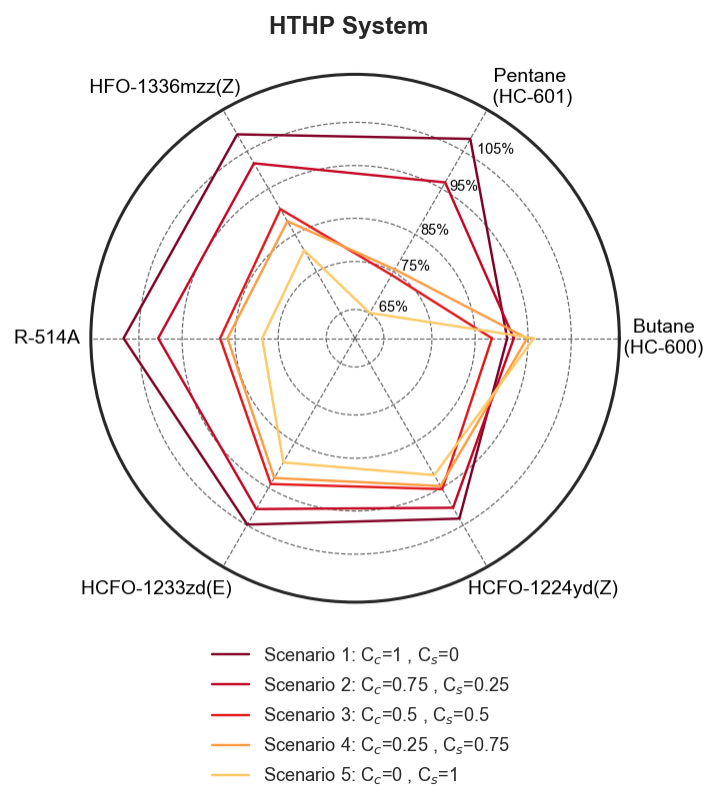

(a)

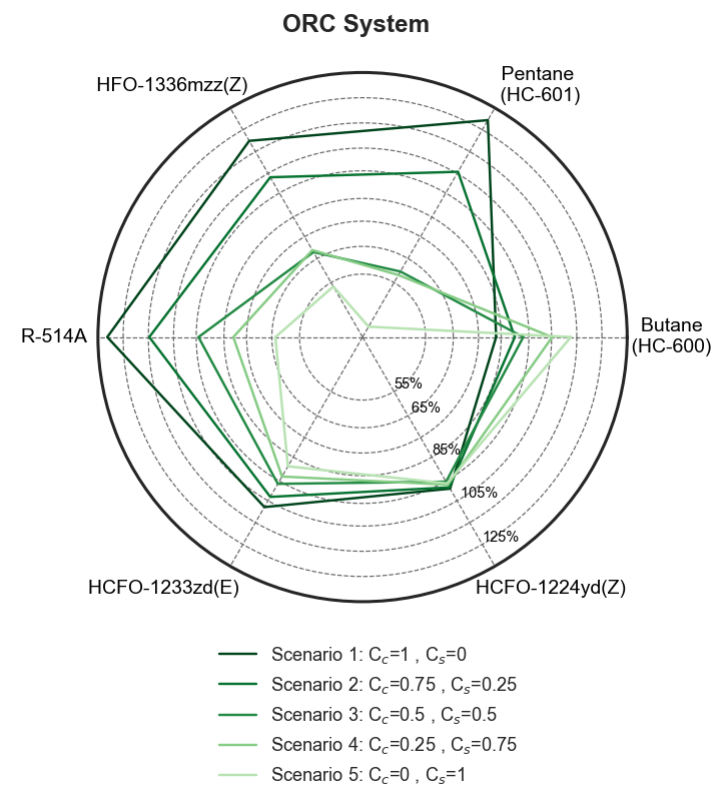

(b)

Fig. 18. Multi-objective evaluation of alternative low-GWP refrigerants in different scenarios, operating only in: a) HTHP mode and b) ORC mode.

Following the main objective of this paper, Fig. 19 shows the multi-objective optimised evaluation of different alternative low-GWP refrigerants to replace HFC-245fa in the proposed technology. Similar to the previous comparison, Pentane. HFO-1336mzz(Z) and R-514A are the proper candidates from an energy efficiency point of view, whereas Butane, HCFO-1233zd(E) and HCFO-1224yd(Z) stand out for their lower installation size requirements. Nevertheless, an optimal selection will be a trade-off between energy efficiency and the installation size requirements, which corresponds to scenario 3. In this case, HCFO-1233zd(E) and HCFO$1224 \mathrm{yd}(\mathrm{Z})$ are the most appropriate low-GWP alternative to replace HFC-245fa with a significant GWP reduction. 


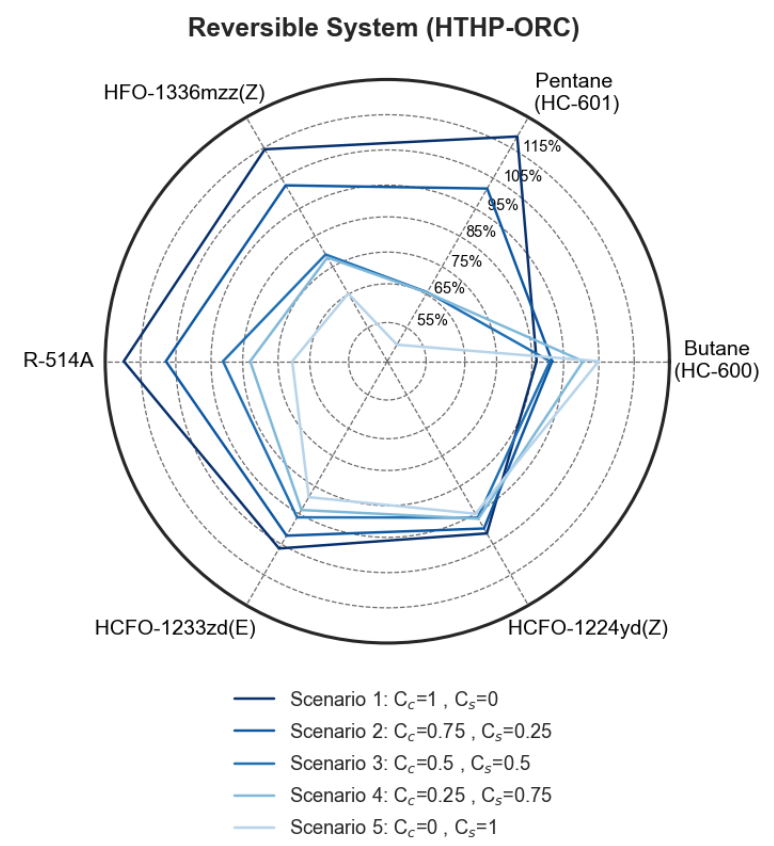

Fig. 19. Multi-objective evaluation of alternative low-GWP refrigerants in different scenarios, operating as a reversible system.

\section{Conclusions}

In this paper, we presented a novel reversible HTHP-ORC system for industrial low-grade waste heat recovery. The focus was set on the optimisation analysis and multi-objective low-GWP alternative refrigerant selection to provide guidelines for further design improvement and sustainable development. To this end, a twofold approach was followed:

1. A reversible HTHP-ORC system was modelled, based on compressor and expander semiempirical validated models to provide a comprehensive energy performance and volumetric machines efficiencies evaluation. Moreover, system parameters as built-in volume ratio and IHX were optimised in order to maximise the energy performance working in both HTHP-ORC modes.

2. The semi-empirical performance and efficiencies results from the reversible model using HFC-245fa were used as a reference to realise an alternative low-GWP refrigerants evaluation. Pentane, Butane, HFO-1336mzz(Z), R-514A, HCFO-1233zd(E) and HCFO$1224 \mathrm{yd}(\mathrm{Z})$ were proposed as potential candidates to replace the currently used HFC$245 \mathrm{fa}$. System optimisation of each alternative working fluid was realised along with a multi-objective evaluation for a proper working fluid selection.

The following conclusions can be drawn from the results of this study:

- The novel HTHP-ORC system proposed provides a significant performance improvement for low-grade waste heat recovery. At the middle evaporating temperature of $85{ }^{\circ} \mathrm{C}$, a COP of 2.22 is achieved condensing at $140{ }^{\circ} \mathrm{C}$, working as HTHP mode, whereas the ORC mode achieves a net electrical efficiency of $7.25 \%$ at a condensing temperature of $40{ }^{\circ} \mathrm{C}$. The highest performance results are a COP of 2.44 and a net electric efficiency of $8.75 \%$, both considering an evaporating temperature of $100^{\circ} \mathrm{C}$.

- The semi-empirical computational evaluation shows that higher heat source temperatures will increase the energy efficiency of the system. About the system architecture, different power capacities for the electric motor and generator are required. Therefore, a single 
component can be used as compressor or expander, but electric motor and generator should be different.

- The multi-objective optimised selection for alternative low-GWP refrigerants shows that HCFO-1233zd(E) and HCFO-1224yd(Z) were the proper refrigerants to replace HFC$245 \mathrm{fa}$ in the proposed reversible system from energy efficiency and installation size points of view. These refrigerants present a COP improvement of $9.7 \%$ and $5.8 \%$ compared to HFC-245fa, respectively, and electrical net efficiency improvement of $2.1 \%$ and $0.8 \%$, respectively, at an evaporating temperature of $90{ }^{\circ} \mathrm{C}$. These refrigerants represent a proper trade-off between the energy performance and installation size compared with HFC-245fa.

\section{Acknowledgements}

The authors acknowledge the Spanish Government for the financial support under projects RTC2017-6511-3 and Adrián Mota-Babiloni through the postdoctoral grant FJCI-2016-28324. Furthermore, the authors acknowledge the Universitat Jaume I (Castelló de la Plana, Spain) for the financial support under the projects UJI-B2018-24 and Carlos Mateu-Royo for the funding received through the $\mathrm{PhD}$ grant PREDOC/2017/41. Finally, the authors acknowledge the Regional Government for the financial support under grant FEDEGENT/2018/002.

\section{References}

[1] European Parliament. Directive 2012/27/EU of the European Parliament and of the Council on energy efficiency. 2012. doi:10.3000/19770677.L_2012.315.eng.

[2] United Nations. Paris Climate Change Conference-November 2015, COP 21. Adopt. Paris Agreem., 2015. doi:FCCC/CP/2015/L.9/Rev.1.

[3] The European Paliament and the Council of the European Union. Directive (Eu) 2018/843 of the European Parliament and of the Council. Off J Eur Union 2018;2018:43-74.

[4] IPCC. Climate Change 2014: Synthesis Report. Contribution of Working Groups I, II and III to the Fifth Assessment Report of the Intergovernmental Panel on Climate Change [Core Writing Team, R.K. Pachauri and L.A. Meyer (eds.)]. Geneva, Switzerland, 2014.

[5] Arpagaus C, Bless F, Uhlmann M, Schiffmann J, Bertsch SS. High temperature heat pumps: Market overview, state of the art, research status, refrigerants, and application potentials. Energy 2018;152:985-1010. doi:10.1016/J.ENERGY.2018.03.166.

[6] Papapetrou M, Kosmadakis G, Cipollina A, La Commare U, Micale G. Industrial waste heat: Estimation of the technically available resource in the EU per industrial sector, temperature level and country. Appl Therm Eng 2018;138:207-16. doi:10.1016/J.APPLTHERMALENG.2018.04.043.

[7] Woolley E, Luo Y, Simeone A. Industrial waste heat recovery: A systematic approach. Sustain Energy Technol Assessments 2018;29:50-9. doi:10.1016/J.SETA.2018.07.001.

[8] Forman C, Muritala IK, Pardemann R, Meyer B. Estimating the global waste heat potential. Renew Sustain Energy Rev 2016;57:1568-79. doi:10.1016/j.rser.2015.12.192. 
[9] Oluleye G, Jobson M, Smith R, Perry SJ. Evaluating the potential of process sites for waste heat recovery. Appl Energy 2016;161:627-46.

doi:10.1016/j.apenergy.2015.07.011.

[10] Jouhara H, Khordehgah N, Almahmoud S, Delpech B, Chauhan A, Tassou SA. Waste heat recovery technologies and applications. Therm Sci Eng Prog 2018;6:268-89. doi:10.1016/J.TSEP.2018.04.017.

[11] Peris B, Navarro-Esbrí J, Molés F, Mota-Babiloni A. Experimental study of an ORC (organic Rankine cycle) for low grade waste heat recovery in a ceramic industry. Energy 2015;85:534-42. doi:10.1016/J.ENERGY.2015.03.065.

[12] Law R, Harvey A, Reay D. A knowledge-based system for low-grade waste heat recovery in the process industries. Appl Therm Eng 2016;94:590-9.

doi:10.1016/J.APPLTHERMALENG.2015.10.103.

[13] Oluleye G, Smith R, Jobson M. Modelling and screening heat pump options for the exploitation of low grade waste heat in process sites. Appl Energy 2016;169:267-86. doi:10.1016/j.apenergy.2016.02.015.

[14] Xia L, Liu R, Zeng Y, Zhou P, Liu J, Cao X, et al. A review of low-temperature heat recovery technologies for industry processes. Chinese J Chem Eng 2018. doi:10.1016/J.CJCHE.2018.11.012.

[15] Meyers S, Schmitt B, Vajen K. The future of low carbon industrial process heat: A comparison between solar thermal and heat pumps. Sol Energy 2018;173:893-904. doi:10.1016/J.SOLENER.2018.08.011.

[16] Brückner S, Liu S, Miró L, Radspieler M, Cabeza LF, Lävemann E. Industrial waste heat recovery technologies: An economic analysis of heat transformation technologies. Appl Energy 2015;151:157-67. doi:10.1016/j.apenergy.2015.01.147.

[17] Dumont O. Investigation of a heat pump reversible into an organic Rankine cycle and its application in the building sector 2017:236. doi:10.13140/RG.2.2.19499.13604.

[18] Dumont o., Carmo C, Randaxhe F, Quoilin S, Lemort V. Performance Comparison of Two Types of Technologies Associated with a Positive Energy Building: a Reversible Heat Pump/orc Unit and a Heat Pump Coupled with PV Panels 2017:1-6. doi:10.18086/swc.2015.04.13.

[19] Quoilin S, Dumont O, Harley Hansen K, Lemort V. Design, Modeling, and Performance Optimization of a Reversible Heat Pump/Organic Rankine Cycle System for Domestic Application. J Eng Gas Turbines Power 2015;138:011701. doi:10.1115/1.4031004.

[20] Carmo C, Nielsen MP, Elmegaard B, Dumont O. Performance Evaluation of a HP / ORC ( Heat Pump / Organic Rankine Cycle ) System with Optimal Control of Sensible Thermal Storage. Int Compress Eng Refrig Air Cond High Perform Build Conf 2016:110 .

[21] Schimpf S, Span R. Simulation of a solar assisted combined heat pump - Organic rankine cycle system. Energy Convers Manag 2015;102:151-60. doi:10.1016/j.enconman.2015.01.083.

[22] Staub S, Bazan P, Braimakis K, Müller D, Regensburger C, Scharrer D, et al. Reversible heat pump-organic rankine cycle systems for the storage of renewable electricity. 
Energies 2018;11. doi:10.3390/en11061352.

[23] Hu B, Xu S, Wang RZ, Liu H, Han L, Zhang Z, et al. Investigation on advanced heat pump systems with improved energy efficiency. Energy Convers Manag 2019;192:16170. doi:10.1016/J.ENCONMAN.2019.04.031.

[24] Urbanucci L, Bruno JC, Testi D. Thermodynamic and economic analysis of the integration of high-temperature heat pumps in trigeneration systems. Appl Energy 2019;238:516-33. doi:10.1016/J.APENERGY.2019.01.115.

[25] Johnson I, Choate WT, Davidson A. Waste Heat Recovery. Technology and Opportunities in U.S. Industry. 2008. doi:10.2172/1218716.

[26] Mateu-Royo C, Navarro-Esbrí J, Mota-Babiloni A, Amat-Albuixech M, Molés F. Theoretical evaluation of different high-temperature heat pump configurations for lowgrade waste heat recovery. Int J Refrig 2018. doi:10.1016/j.ijrefrig.2018.04.017.

[27] Cao X-Q, Yang W-W, Zhou F, He Y-L. Performance analysis of different hightemperature heat pump systems for low-grade waste heat recovery. Appl Therm Eng 2014;71:291-300. doi:10.1016/j.applthermaleng.2014.06.049.

[28] Mota-Babiloni A, Mateu-Royo C, Navarro-Esbrí J, Molés F, Amat-Albuixech M, Barragán-Cervera Á. Optimisation of high-temperature heat pump cascades with internal heat exchangers using refrigerants with low global warming potential. Energy 2018;165:1248-58. doi:10.1016/j.energy.2018.09.188.

[29] Yang W, Cao X, He Y, Yan F. Theoretical study of a high-temperature heat pump system composed of a $\mathrm{CO} 2$ transcritical heat pump cycle and a $\mathrm{R} 152 \mathrm{a}$ subcritical heat pump cycle. Appl Therm Eng 2017;120:228-38. doi:10.1016/J.APPLTHERMALENG.2017.03.098.

[30] Bamigbetan O, Eikevik TM, Nekså P, Bantle M. Review of vapour compression heat pumps for high temperature heating using natural working fluids. Int J Refrig 2017;80:197-211. doi:10.1016/j.ijrefrig.2017.04.021.

[31] Mateu-Royo C, Navarro-Esbrí J, Mota-Babiloni A, Amat-Albuixech M, Molés F. Thermodynamic analysis of low GWP alternatives to HFC-245fa in high-temperature heat pumps: HCFO-1224yd(Z), HCFO-1233zd(E) and HFO-1336mzz(Z). Appl Therm Eng 2019. doi:10.1016/j.applthermaleng.2019.02.047.

[32] Frate GF, Ferrari L, Desideri U. Analysis of suitability ranges of high temperature heat pump working fluids. Appl Therm Eng 2019;150:628-40.

doi:10.1016/J.APPLTHERMALENG.2019.01.034.

[33] Zühlsdorf B, Jensen JK, Elmegaard B. Heat pump working fluid selection — economic and thermodynamic comparison of criteria and boundary conditions. Int J Refrig 2019;98:500-13. doi:10.1016/J.IJREFRIG.2018.11.034.

[34] Mateu-Royo C, Navarro-Esbrí J, Mota-Babiloni A, Molés F, Amat-Albuixech M. Experimental exergy and energy analysis of a novel high-temperature heat pump with scroll compressor for waste heat recovery. Appl Energy 2019;253:113504. doi:10.1016/j.apenergy.2019.113504.

[35] Bamigbetan O, Eikevik TM, Nekså P, Bantle M, Schlemminger C. Experimental investigation of a prototype R-600 compressor for high temperature heat pump. Energy 
2019;169:730-8. doi:10.1016/J.ENERGY.2018.12.020.

[36] Bamigbetan O, Eikevik TM, Nekså P, Bantle M, Schlemminger C. The development of a hydrocarbon high temperature heat pump for waste heat recovery. Energy 2019;173:1141-53. doi:10.1016/J.ENERGY.2019.02.159.

[37] Chamoun M, Rulliere R, Haberschill P, Peureux J-L. Experimental and numerical investigations of a new high temperature heat pump for industrial heat recovery using water as refrigerant. Int J Refrig 2014;44:177-88. doi:10.1016/j.ijrefrig.2014.04.019.

[38] Bobelin D, Bourig A, Peureux J. Experimental results of a newly developed very high temperature industrial heat pump $\left(140^{\circ} \mathrm{C}\right)$ equipped with scroll compressors and working with a new blend refrigerant. Int Refrig Air Cond Conf 2012.

[39] Arpagaus C, Bless F, Uhlmann M, Büchel E, Frei S, Schiffmann J, et al. High temperature heat pump using HFO and HCFO refrigerants - System design , simulation, and first experimental results. 17th Int Refrig Air Cond Conf Purdue, July 9-12, 2018 2018:1-10.

[40] Pethurajan V, Sivan S, Joy GC. Issues, comparisons, turbine selections and applications - An overview in organic Rankine cycle. Energy Convers Manag 2018;166:474-88. doi:10.1016/J.ENCONMAN.2018.04.058.

[41] Mahmoudi A, Fazli M, Morad MR. A recent review of waste heat recovery by Organic Rankine Cycle. Appl Therm Eng 2018;143:660-75. doi:10.1016/J.APPLTHERMALENG.2018.07.136.

[42] Braimakis K, Karellas S. Energetic optimization of regenerative Organic Rankine Cycle (ORC) configurations. Energy Convers Manag 2018;159:353-70. doi:10.1016/J.ENCONMAN.2017.12.093.

[43] Landelle A, Tauveron N, Haberschill P, Revellin R, Colasson S. Organic Rankine cycle design and performance comparison based on experimental database. Appl Energy 2017;204:1172-87. doi:10.1016/J.APENERGY.2017.04.012.

[44] Park B-S, Usman M, Imran M, Pesyridis A. Review of Organic Rankine Cycle experimental data trends. Energy Convers Manag 2018;173:679-91. doi:10.1016/J.ENCONMAN.2018.07.097.

[45] Xia XX, Wang ZQ, Hu YH, Zhou NJ. A novel comprehensive evaluation methodology of organic Rankine cycle for parameters design and working fluid selection. Appl Therm Eng 2018;143:283-92. doi:10.1016/J.APPLTHERMALENG.2018.07.061.

[46] Zhi L-H, Hu P, Chen L-X, Zhao G. Thermodynamic analysis of a novel transcriticalsubcritical parallel organic Rankine cycle system for engine waste heat recovery. Energy Convers Manag 2019;197:111855. doi:10.1016/J.ENCONMAN.2019.111855.

[47] Imran M, Haglind F, Asim M, Zeb Alvi J. Recent research trends in organic Rankine cycle technology: A bibliometric approach. Renew Sustain Energy Rev 2018. doi:10.1016/j.rser.2017.08.028.

[48] Mateu-Royo C, Navarro-Esbrí J, Mota-Babiloni A, Amat-Albuixech M, Molés F. Thermodynamic analysis of low GWP alternatives to HFC-245fa in high-temperature heat pumps: HCFO-1224yd(Z), HCFO-1233zd(E) and HFO-1336mzz(Z). Appl Therm Eng 2019. doi:10.1016/j.applthermaleng.2019.02.047. 
[49] Dumont O, Parthoens A, Dickes R, Lemort V. Experimental investigation and optimal performance assessment of four volumetric expanders (scroll, screw, piston and roots) tested in a small-scale organic Rankine cycle system. Energy 2018;165:1119-27. doi:10.1016/J.ENERGY.2018.06.182.

[50] Lemort V. Contribution to the characterization of scroll machines in compressor and expander modes. PhD Thesis, Thermodyn Lab Aerosp Mech Eng Dep Univ Liège 2008.

[51] Winandy E, O CS, Lebrun J. Experimental analysis and simplified modelling of a hermetic scroll refrigeration compressor. Appl Therm Eng 2002;22:107-20. doi:10.1016/S1359-4311(01)00083-7.

[52] Winandy E, Saavedra O C, Lebrun J. Simplified modelling of an open-type reciprocating compressor. Int J Therm Sci 2002;41:183-92. doi:10.1016/S1290-0729(01)01296-0.

[53] Cuevas C, Lebrun J, Lemort V, Winandy E. Characterization of a scroll compressor under extended operating conditions. Appl Therm Eng 2010;30:605-15. doi:10.1016/J.APPLTHERMALENG.2009.11.005.

[54] Lemort V, Quoilin S, Cuevas C, Lebrun J. Testing and modeling a scroll expander integrated into an Organic Rankine Cycle. Appl Therm Eng 2009;29:3094-102. doi:10.1016/J.APPLTHERMALENG.2009.04.013.

[55] Peris B, Navarro-Esbrí J, Molés F, Mota-Babiloni A, Amat-Albuixech M, Mateu-Royo $\mathrm{C}$, et al. Low GWP working fluids for reversible systems of high temperature heat pump and organic rankine cycle (HTHP/ORC). 13th IIR Gustav Lorentzen Conf Nat Refrig Nat Refrig Solut Warm Clim Ctries (GL 2018) Val 2018.

[56] Incropera FP, De Witt DP. Fundamentals of heat and mass transfer. New York J Wiley 2002.

[57] ASHRAE. ASHRAE Handbook Fundamentals. Am Soc Heating, Refrig AirConditioning Eng 2017.

[58] Hughes J, Juhasz J. Low GWP Refrigerant Solutions for Heat Pumps. Chemours Co 2019.

[59] Chemours. Opteon ${ }^{\mathrm{TM}}$ XP30 (R-514A), Technical information 2019:1-16.

[60] Honeywell. Solstice® zd, Technical information 2015:1-5.

[61] AGC Chemicals. AMOLEA® 1224yd, Technical information. ASAHI Glas Co 2017:118. 